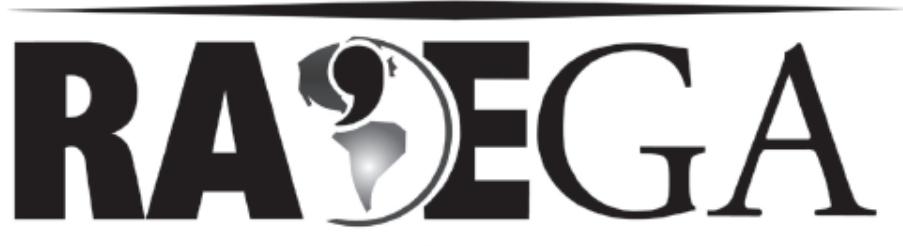

O ESPAÇO GEOGRÁFICO EM ANÁLISE

\title{
IMPACTOS MICROCLIMÁTICOS DO DESENHO URBANO: ESTUDOS REALIZADOS EM CURITIBA
}

\section{MICROCLIMATE IMPACTS OF URBAN DESIGN: STUDIES IN CURITIBA}

\author{
Flávia Cristina Osaku Minella \\ Francisco Bemquerer Costa Rasia ${ }^{2}$ \\ Eduardo Leite Krüger ${ }^{3}$
}

\section{RESUMO}

O artigo busca compreender as relações entre atributos da geometria urbana e alterações no microclima. São apresentados dois estudos distintos conduzidos na mesma área central de Curitiba, PR, a partir de medições de campo realizadas em 2009 e de simulações de clima urbano no software ENVI-met. Os estudos, embora utilizem a mesma campanha de coleta de dados,

\footnotetext{
${ }^{1}$ Graduada em arquitetura pela Pontifícia Universidade Católica do Paraná - PUC-PR, mestre em Tecnologia pelo Programa de Pós-Graduação em Tecnologia da UTFPR, doutoranda do Programa de Pós-Graduação em Tecnologia da UTFPR. E-mail: arqui flavia@yahoo.com.br

${ }^{2}$ Graduado em arquitetura pela Universidade Federal do Paraná - UFPR, mestrando do Programa de Pós-Graduação em Tecnologia da UTFPR. E-mail: chico.ix@terra.com.br

${ }^{3}$ Graduado em Engenharia Civil pela Universidade Católica de Petrópolis, mestrado em Planejamento Energético pela COPPE/UFRJ Universidade Federal do Rio de Janeiro, doutorado em Arquitetura pela Universität Hannover, Alemanha e pós-doutorado na Ben-Gurion University of the Negev, Israel. Professor Adjunto de Nível Superior da Universidade Tecnológica Federal do Paraná - UTFPR no Departamento Acadêmico de Construção Civil (UTFPR), professor pesquisador e coordenador da Linha de Pesquisa Tecnologia e Desenvolvimento do Programa de Pós-Graduação em Tecnologia (UTFPR) e professor pesquisador do Programa de Pós-Graduação em Engenharia Civil (UTFPR).

E-mail: ekruger@utfpr.edu.br
} 
possuem objetivos e metodologias diferentes. O primeiro estudo foca no impacto da geometria urbana, na temperatura ambiente e nos níveis de conforto em ruas de pedestre no período diurno, sendo o fator de visão do céu utilizado como indicador da complexa geometria urbana. O segundo estudo trata do impacto da orientação das vias em relação ao vento dominante, quanto às taxas de ventilação resultantes (velocidade do ar e distribuição espacial), visando à dispersão de poluentes gerados pelo tráfego, no contexto urbano. Os resultados auferidos evidenciam a influência da forma urbana para a determinação do conforto térmico em ruas de pedestres, restringindo-se a um período diurno específico, e para a criação de cenários de poluição.

Palavras-chaves: conforto térmico, fator de visão do céu, qualidade do ar, ENVI-met.

\begin{abstract}
This paper seeks to understand the relations between attributes of the urban morphology and changes in the microclimate. Two independent studies, carried out in downtown Curitiba, Paraná, are presented, from field measurements in 2009 and urban climate simulations using the ENVI-met software suite. Both studies, whereas dealing with the same physical area, have distinct objectives and workflows. The first study focuses on the impact of street geometry on the ambient temperature and pedestrian comfort levels in daytime, using the skyview factor as an indicator of the complexity of the urban geometry. The second study evaluates the impact of street orientation in relation to prevailing winds and the resulting effects of ventilation (air speed and spatial distribution) on the dispersion of traffic-generated air pollutants. The results show the influence of urban geometry on human thermal comfort in pedestrian streets and on the outcome of pollutant dispersion scenarios.
\end{abstract}

Keywords: thermal comfort, sky-view factor, air quality, ENVI-met

\title{
INTRODUÇÃO
}

Grande parte do crescimento urbano ocorre em latitudes subtropicais. A urbanização em tais áreas levou ao adensamento e à expansão horizontal das cidades. Essas duas estratégias, em geral não planejadas devidamente, podem trazer conseqüências ambientais significativas. Entretanto, um bom planejamento de cidades, que leve em conta efeitos climáticos de modificações na estrutura e configuração urbanas, pode mitigar impactos das mudanças climáticas que ocorrem em um nível mais macro, contribuindo para menor desconforto térmico localizado. 
A análise de fenômenos relacionados ao clima urbano, conseqüência de um processo generalizado de urbanização em diversas partes do mundo, pode e deve servir de subsídio para o planejamento urbano. De estudos elaborados nessa área, a relação entre fatores controláveis pelo homem, como, por exemplo, taxa de permeabilidade do solo e distanciamento ótimo de prédios entre si, juntamente com restrições à sua altura, pode ser melhor definida, com níveis mais elevados de conforto e decorrente redução de consumo energético para climatização ou iluminação artificial de edificações. A expectativa é que, com o agravamento das condições climáticas (alagamentos, ondas de calor etc), estudos relacionados ao clima urbano e, mais especificamente, que visem à mitigação dos efeitos das mudanças climáticas por meio de medidas adequadas de planejamento urbano, ganhem maior peso, tornando-se uma necessidade.

Na cidade de São Paulo, por exemplo, observa-se com freqüência cada vez maior alagamentos e transbordamentos de rios, como o Tietê, que, mesmo tendo sido alargados, têm sua capacidade excedida. Pode-se relacionar este fato à supressão de áreas vegetadas em favor de pavimentação e construções, impermeabilizando grandes áreas da cidade e gerando grandes eflúvios. O projeto "Nova Marginal do Tietê" tem gerado polêmica, com a previsão de novas pistas, sem haver um projeto urbanístico, em contrapartida, que minimize o impacto de novas áreas pavimentadas.

O planejamento das cidades futuras poderia mitigar os efeitos globais relacionados às mudanças climáticas e até mesmo aliviar os impactos de grandes concentrações urbanas (geração de calor, poluentes, alterações nos padrões de vento e de precipitações, etc), em um feedback negativo. Um exemplo da utilização de estratégias de planejamento urbano com implicações microclimáticas na recuperação de áreas urbanas degradadas foi um projeto recente de recuperação de um trecho de rio na zona urbana, em Seul, na Coréia do Sul. Recursos computacionais da área de climatologia urbana foram também utilizados (a ferramenta de simulação de clima urbano, ENVI-Met) para se verificar os impactos de alterações urbanas no microclima (HAN; MUN; $\mathrm{HUH}, 2007)$. 
Em vista disso, o presente artigo tem por objetivo discutir relações entre atributos da geometria urbana e alterações no microclima. Dois estudos distintos são apresentados, ambos conduzidos na área urbana de Curitiba, PR, a partir de medições de campo realizadas em 2009 e de simulações de clima urbano no software ENVI-met.

Dois enfoques serão tratados:

- O impacto da geometria urbana, aqui representada pelo fator de visão do céu ( $F V C$ ), na temperatura ambiente e nos níveis de conforto em ruas de pedestre no período diurno - estudo 1 ;

- O impacto da orientação das vias em relação ao vento dominante, quanto às taxas de ventilação resultantes (velocidade do ar e distribuição espacial), visando à dispersão de poluentes gerados pelo tráfego, no contexto urbano - estudo 2.

\section{ÁREA DE ESTUDO}

Curitiba encontra-se na região sul do Brasil, latitude $25^{\circ} 31^{\prime} \mathrm{S}$, longitude $49^{\circ} 11^{\prime} \mathrm{W}$ e altitude de $917 \mathrm{~m}$ acima do nível do mar. Abrange uma área de 435 $\mathrm{km}^{2}$ e possui uma população de aproximadamente 1.800 .000 habitantes (IBGE, 2009). A cidade situa-se abaixo do Trópico de Capricórnio, no primeiro planalto paranaense. De acordo com a classificação de Köppen-Geiger, o clima de Curitiba é predominantemente mesotérmico com verões frescos $(\mathrm{Cfb})$, com invernos tipicamente secos (IPPUC, 2009). As precipitações são da ordem de $1600 \mathrm{~mm}$ anuais. Segundo o Zoneamento Bioclimático Brasileiro (ABNT, 2004), Curitiba está na Zona Bioclimática I, a mais fria das oito zonas, correspondente a $0,8 \%$ do território nacional. Medições meteorológicas oficiais são realizadas pelo INMET em uma estação no Centro Politécnico da UFPR, na região leste da cidade. A temperatura máxima média é $26^{\circ} \mathrm{C}$ e a mínima média é $7.4^{\circ} \mathrm{C}$. Os ventos dominantes sopram de leste, nordeste e sudeste, com médias entre 2 e 3 m/s (LAMBERTS; GOULART; FIRMINO, 1998). 
O foco deste estudo é o calçadão da Rua XV de Novembro, na região central da cidade. Como primeira rua de pedestres criada no Brasil nos anos de 1970, sua importância histórica é amplamente reconhecida. O calçadão é composto por cinco quadras da Rua XV de Novembro, iniciando-se a partir da Rua Presidente Faria até a Travessa Oliveira Bello, e pelas duas quadras que compõem a Avenida Luis Xavier. Todo o calçadão, somadas as duas praças situadas nas extremidades (Praça Santos Andrade e Praça General Osório), é considerado patrimônio histórico. As construções ao longo da Rua XV de Novembro representam várias décadas: sobrados construídos em final do século XIX e começo do século $\mathrm{XX}$, prédios art-déco de cinco e seis pavimentos das décadas de 1940 e 1950, arranha-céus modernistas dos anos 1960-1970.

Atualmente, a Rua das Flores, como é popularmente chamada, faz parte da identidade cultural da cidade, sendo caracterizada por um fluxo intenso e constante de transeuntes. Segundo a Associação Comercial do Paraná (2007), 140.000 pessoas circulam por dia pelo calçadão. Desde seu surgimento, a via é uma das principais artérias comerciais da cidade. O calçadão está implantado em um eixo de rua com tendência para o sentido $E-W$, com um azimute próximo a $70^{\circ}$. Além da Rua XV de Novembro, foram consideradas ruas de pedestres no entorno do calçadão, sendo estas: Rua Saldanha Marinho, Praça Generoso Marques, Travessa Oliveira Bello e a Rua Senador Alencar Guimarães.

\section{IMPACTOS DO FATOR DE VISÃO DO CÉU (FVC) NA TEMPERATURA AMBIENTE E NOS NÍVEIS DE CONFORTO EM RUAS DE PEDESTRES - ESTUDO 1}

Os modelos de cânion urbano consideram edificações com alturas uniformes. No entanto, em geral, esta simplificação não condiz com a forma urbana da maioria das cidades, que apresentam edificações com perfis verticais diversificados. Nesse sentido, o fator de visão do céu (FVC), 
representado pelo símbolo $\Psi$ s, pode ser considerado um parâmetro mais próximo da realidade.

O fator de visão do céu é a razão entre a porção de céu visível de um determinado ponto e o céu potencialmente disponível a partir deste ponto (CHAPMAN, 2007). Johnson e Watson (1984) consideram o FVC como a razão entre a radiação solar recebida (ou emitida) por uma superfície plana comparada com aquela recebida (ou emitida) por todo o entorno.

O valor do FVC varia de 0 (zero) até 1, sendo que o valor 1 corresponde a uma área sem qualquer obstáculo que se interponha entre o ponto escolhido e o céu.

O FVC tem sido comumente utilizado em estudos de trocas de energia (CHAPMAN; THORNES, 2004). Embora parâmetros como o calor liberado pelas ações antropogênicas e as propriedades térmicas dos materiais estejam relacionados com a intensidade da ilha de calor noturna, simulações realizadas por Oke et al. ${ }^{4}$ (1991, citado por CHAPMAN; THORNES; BRADLEY, 2001) apontam que o FVC pode, isoladamente, produzir uma $\triangle T$ Tu-r de 5 a $7{ }^{\circ} \mathrm{C}$.

Observa-se que há uma predominância de estudos que relacionam FVC e ilha de calor noturna, comparativamente a estudos que tratam do período diurno. Em relação aos resultados encontrados, nota-se uma divergência entre pesquisas que apontam haver relação entre a geometria urbana, definida pelo FVC, e a temperatura ambiente (UNGER, 2004; SVENSSON, 2004; SOUZA, 2007), e aquelas que demonstram pouca influência do FVC para a determinação da temperatura local (ELIASSON, 1996; UPMANIS; CHEN, 1999).

Apesar de o FVC ser uma simples parametrização, o cálculo para a sua obtenção tem sido um desafio para os climatologistas (CHAPMAN; THORNES, 2004). Diferentes métodos são apresentados para o cálculo de obtenção do FVC. Basicamente, o FVC pode ser obtido por métodos analíticos (OKE, 1981; JOHNSON; WATSON, 1984), métodos fotográficos - uso de programas

\footnotetext{
${ }^{4}$ OKE, T. R. et al. Simulation of surface urban heat islands under 'ideal' conditions at night. Part 2: Diagnosis of causation. Boundary- Layer Meteorology, v. 56, p. 339-358, 1991.
} 
específicos (CHAPMAN; THORNES; BRADLEY, 2001; MOIN; TSUTSUMI, 2004; CORREA et al., 2005), sistemas com dados de base 3D acoplados a um Sistema de Informações Geográficas - SIG (SOUZA; RODRIGUES; MENDES, 2003), sistemas que utilizam GPS (CHAPMAN; THORNES, 2004) e, mais recentemente, imagens com um dispositivo que mostra as diferenças térmicas entre as obstruções e o céu (CHAPMAN et al., 2007).

\section{MATERIAIS E MÉTODOS}

A primeira etapa desta pesquisa consistiu na determinação de pontos passíveis para posterior monitoramento (Erro! Fonte de referência não encontrada.). Procurou-se mapear pontos na extensão que abrange desde a Praça Santos Andrade até a Praça General Osório (pontos 1 a 11), englobando todas as quadras do calçadão da Rua XV de Novembro. Além destes, selecionaram-se pontos no entorno do calçadão: Rua Saldanha Marinho (pontos 12 e 13), Praça Generoso Marques (pontos 14 a 16), Travessa Oliveira Bello (ponto 17) e a Rua Senador Alencar Guimarães (ponto 18).

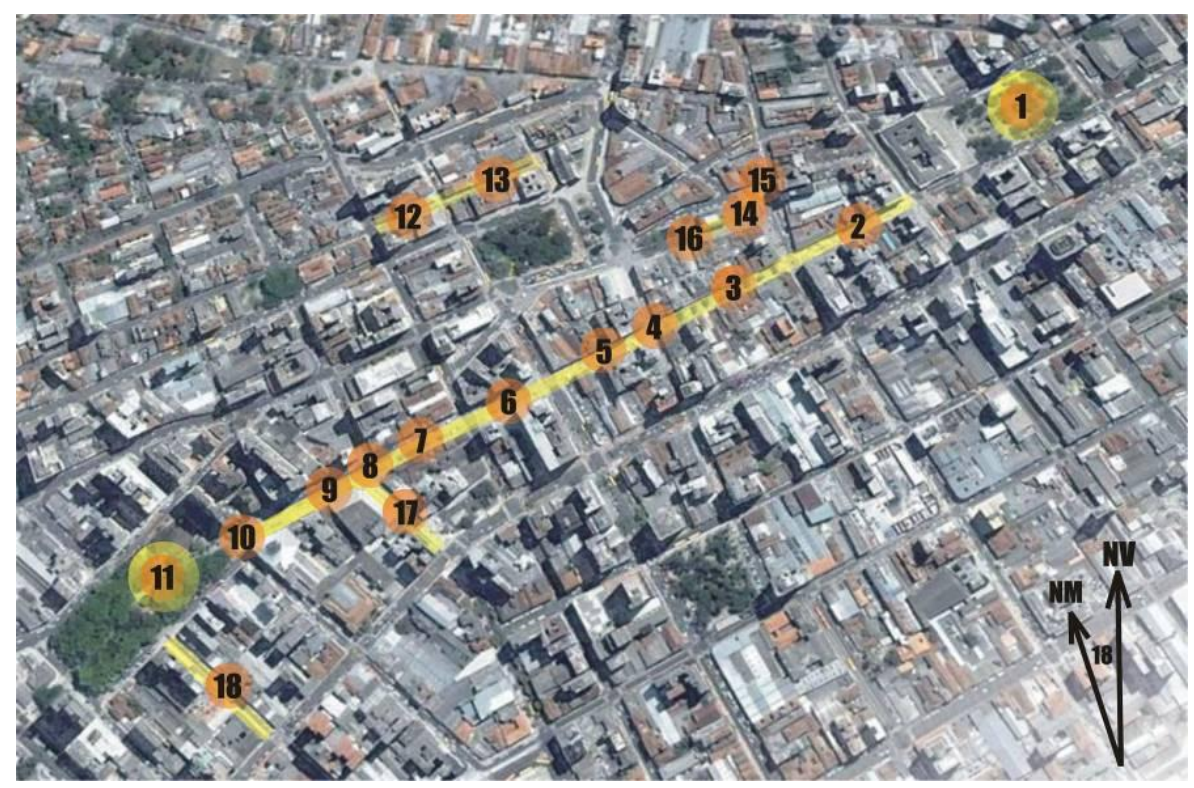

FIGURA 1 - LOCALIZAÇÃO DOS PONTOS SELECIONADOS PARA OBTENÇÃO DO FVC 
Posteriormente, foram obtidas fotos olho de peixe dos pontos aptos a serem monitorados, e calculado o FVC de cada ponto. Para tanto, utilizou-se uma lente olho de peixe FC-E8 acoplada a uma câmera digital Nikon CoolPix 4500, sendo o cálculo do FVC realizado por intermédio do programa Rayman, software desenvolvido por Andreas Matzarakis e de domínio público (http://www.mif.uni-freiburg.de/RayMan/). Das 18 localidades passíveis de monitoramento, que totalizaram 19 pontos, uma vez que o ponto 6 foi subdividido em dois pontos (6a e 6b), selecionaram-se 15 pontos para medição (Figura 2), havendo repetição de alguns pontos.

Os pontos de monitoramento foram sempre centralizados em relação à quadra, exceto nos seguintes locais: ponto 9, uma vez que esta quadra é a única com passagem para veículos; ponto 10, situado no entorno da Praça General Osório; ponto 16, localizado no entorno da Praça Generoso Marques e ponto 6 por haver uma fonte centralizada na quadra.

O monitoramento das variáveis microclimáticas ocorreu sempre em pares e simultaneamente em períodos de quatro horas (início às $11 \mathrm{~h} 01 \mathrm{e}$ término às 15h00). No total, foram 13 dias de monitoramento ao longo dos meses de janeiro a agosto de 2009. Em relação ao estabelecimento dos pares de medição, procurou-se comparar diferentes situações urbanas, como, por exemplo: cânions urbanos com diferenças consideráveis no valor de FVC, como os pares 2 e 7; pares com pouca diferença na quantidade de céu obstruído, como os pontos 8 e 16; comparação de cruzamento de vias com cânion e com praça seca, pares 4 e 9 e pares 4 e 14, respectivamente. Ressalta-se que, embora alguns pares apresentem valores de FVC semelhantes, suas configurações urbanas (regularidade na altura das edificações, ponto em cruzamento de vias, etc.) são distintas. 


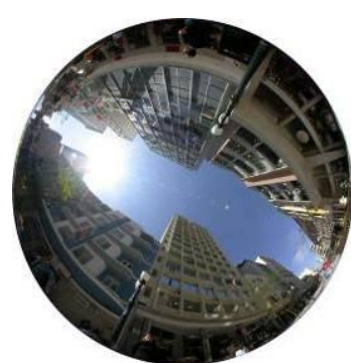

PONTO 2

$\mathrm{FVC}=0,20$

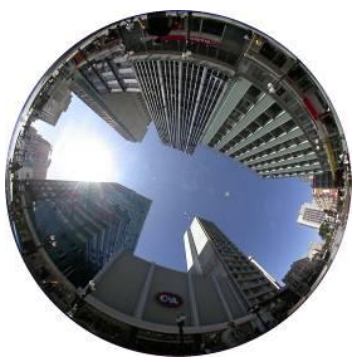

PONTO 6a

$\mathrm{FVC}=0,26$

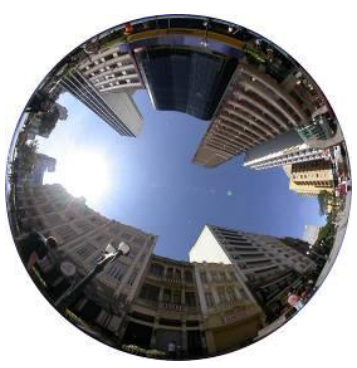

PONTO 9

$\mathrm{FVC}=0,29$

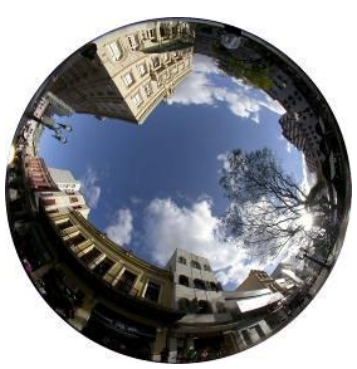

PONTO 16

$\mathrm{FVC}=0,38$

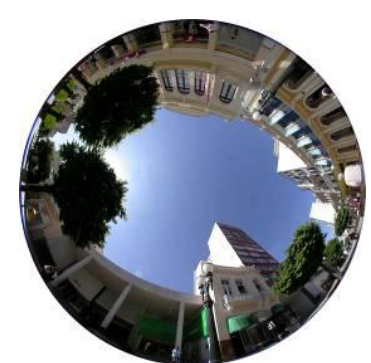

PONTO 3

$\mathrm{FVC}=0,32$

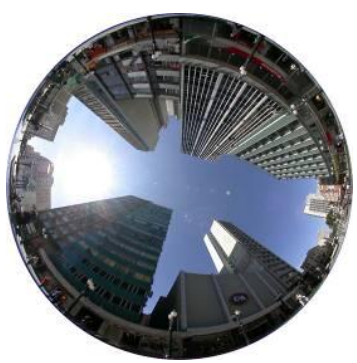

PONTO 6b

$\mathrm{FVC}=0,27$

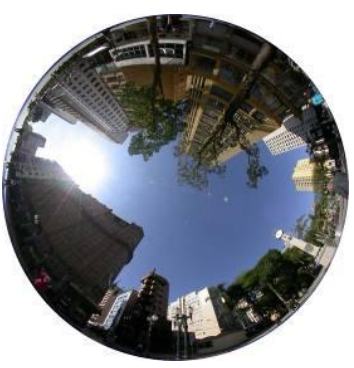

PONTO 10

$\mathrm{FVC}=0,30$

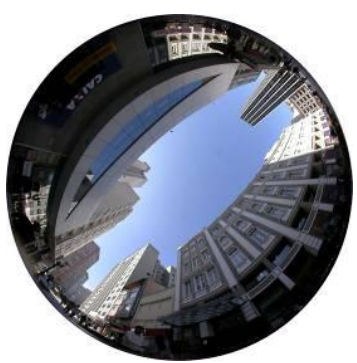

PONTO 17

$\mathrm{FVC}=0,21$

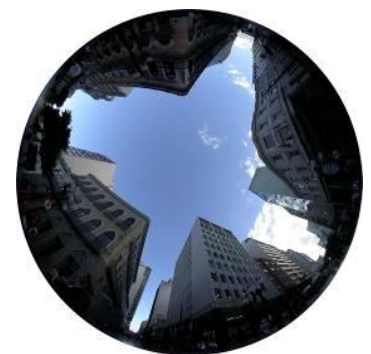

PONTO 4

$\mathrm{FVC}=0,34$

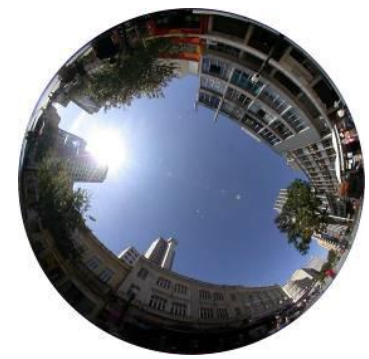

PONTO 7

$\mathrm{FVC}=0,39$

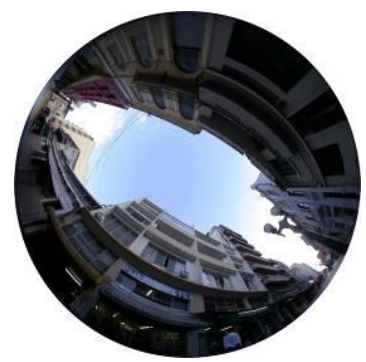

PONTO 13

$\mathrm{FVC}=0,21$

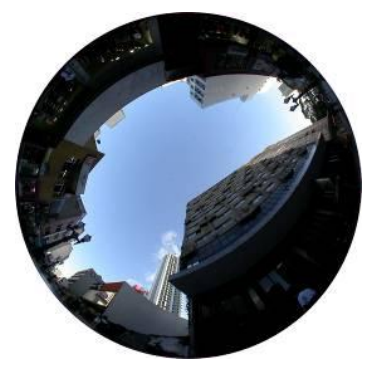

PONTO 18

$\mathrm{FVC}=0,30$

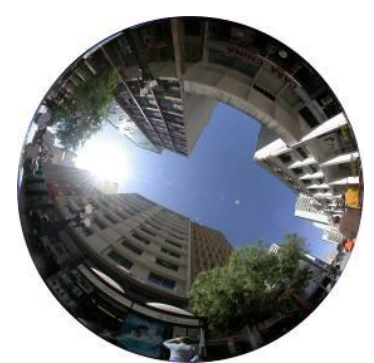

PONTO 5

$\mathrm{FVC}=0,22$

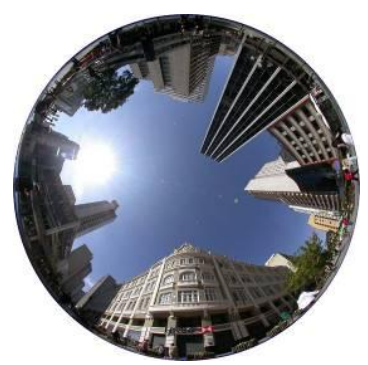

PONTO 8

$\mathrm{FVC}=0,37$

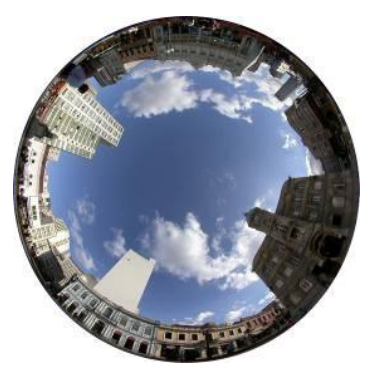

PONTO 14

$\mathrm{FVC}=0,55$

FIGURA 2 - FOTO OLHO DE PEIXE E FVC DOS PONTOS MONITORADOS

As coletas de dados climáticos foram possíveis com o uso de duas estações meteorológicas da marca HOBO modelo H21-001 (Figura 3). Cada 
estação estava equipada com os seguintes instrumentos: sensor de temperatura do ar e umidade, piranômetro e sensor de direção e velocidade do vento (anemômetro). As faixas de precisão desses instrumentos satisfizeram as recomendações da norma ISO 7726 (1998), que dispõe sobre os instrumentos para a medição de variáveis físicas. Os sensores de temperatura do ar e umidade relativa foram fixados na altura de $110 \mathrm{~cm}$, conforme ISO 7726 (1998). O piranômetro foi fixado a $160 \mathrm{~cm}$, acima dos demais sensores e orientado para o Norte, para evitar sombras sobre o mesmo. $\mathrm{O}$ anemômetro foi fixado a $210 \mathrm{~cm}$, conforme recomendado por Campbell (1997).

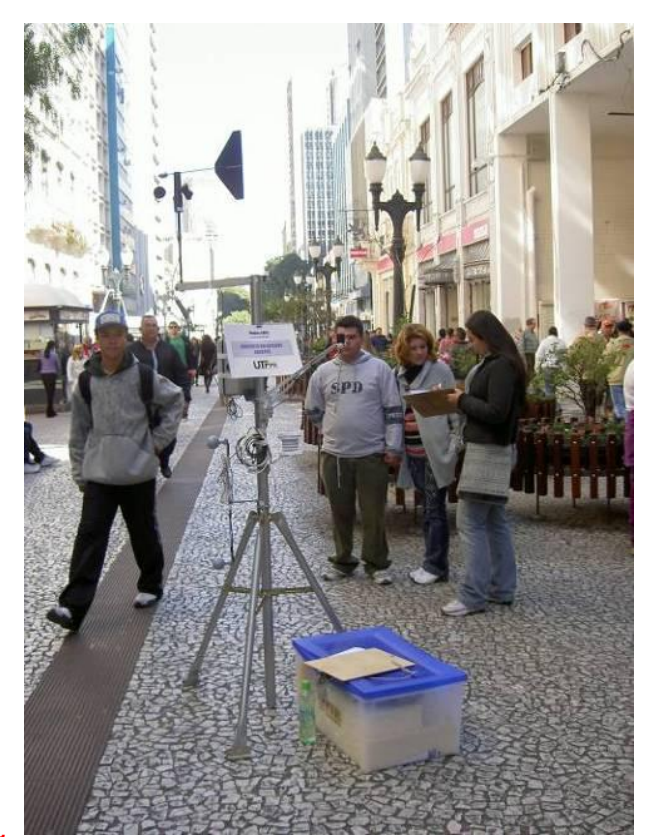

FIGURA 3 - ESTAÇÃO HOBO (H21-001) E INSTRUMENTOS DE MEDIÇÃO ACOPLADOS

Para se obter a temperatura radiante média (Trm), foram utilizados termômetros de globo de cobre, com $\varnothing=2$ ", pintados na cor RAL-7001 (THORSSON et al., 2007). Em cada estação, fixou-se o termômetro de globo a $110 \mathrm{~cm}$ do solo, conforme ISO 7726 (1998). A Trm foi calculada pela fórmula para convecção forçada, definida pela ISO 7726 (1998).

Para que fossem obtidos resultados precisos, os dados climáticos foram gravados de 5 em 5 segundos. Foi feita, então, uma média de todos os segundos para a composição do minuto. Os índices de conforto utilizados 
neste estudo foram: Voto Médio Estimado (PMV) e Temperatura Fisiológica Equivalente (PET). O cálculo de cada um deles foi feito por meio do programa RayMan. As informações pessoais foram baseadas nos dados de um homem padrão segundo a norma ISO 8996 (2004), sendo consideradas as seguintes características: idade 30 anos, altura $1,75 \mathrm{~m}$ e peso $70 \mathrm{~kg}$.

A primeira etapa da análise dos dados consistiu em estabelecer a variável climática com melhor correlação com os índices de conforto selecionados. Desta forma, por meio do programa Statgraphics, foram obtidas correlações entre os índices PMV e PET e as variáveis microclimáticas (velocidade do vento, radiação solar, umidade do ar, temperatura do ar e temperatura radiante média), sendo a temperatura do ar (T) e a temperatura radiante média (Trm) as que apresentaram maiores coeficientes de correlação com os índices de conforto.

O método das medições em pares permite a comparação de duas situações urbanas, mas não de todos os pontos simultaneamente. Por conseguinte, foram adotados os seguintes procedimentos para contornar esta condição:

\section{- Análise dos pares de medição}

Baseando-se unicamente no conceito de FVC, partiu-se do pressuposto de que, sob condições diurnas, em pontos com maior abertura do céu, as variáveis $\mathrm{T}$ e Trm seriam proporcionalmente maiores que em pontos com menor valor de FVC, devido à maior exposição das superfícies urbanas à radiação solar. Assim, para o período de medição, procurou-se verificar a existência de um comportamento padrão entre os valores médios de Trm dos pares de medição e os respectivos valores de FVC.

\section{- Seleção e análise de "dias comparáveis"}

O objetivo dessa etapa foi analisar o comportamento térmico de pares monitorados e o nível de conforto térmico em dias selecionados, associando o valor de FVC a estas análises. Uma vez que a análise climatológica de espaços abertos abrange uma diversidade de variáveis climáticas, sendo uma 
das mais impactantes a radiação solar recebida no ponto, utilizou-se a diferença de radiação entre os pares de medição, segundo a Equação 1, como parâmetro para a seleção de "dias comparáveis". O resultado é dado em diferenças percentuais entre o total de radiação solar incidente nos pares de medição.

$$
\begin{aligned}
& \% \text { VARIAÇÃO }=\left[\left(\Sigma \lg 2^{-} \Sigma \lg _{1}\right) / \quad \text { Equação } 1\right. \\
& \left.\Sigma \lg _{2}\right] \times 100
\end{aligned}
$$

Sendo $\Sigma \lg 2$ é o total de radiação medido na estação 2, e $\Sigma \lg 1$ é o total de radiação medido na estação 1 , sendo considerados os dados do período de monitoramento das $11 \mathrm{~h} 01$ às $15 \mathrm{~h} 00$.

Para os dias com diferença de radiação entre os pontos inferior a $30 \%$ foram traçados gráficos relacionando a diferença de Trm entre os pontos (estação 2- estação 1) e os índices PMV e PET. Em seguida, foram comparados os níveis de conforto calculado entre os pares. O valor de referência, $30 \%$, foi determinado em função dos valores de radiação encontrados nos 13 dias de medição.

\section{- Normalização de dados e análises}

A etapa seguinte foi a normalização dos dados de Trm para que fosse possível comparar dias diferentes de monitoramento, evitando-se, assim, que as diferentes condições meteorológicas de cada dia mascarassem o efeito do FVC. A normalização de dados para uma mesma condição depende de um fator estabelecido por outra situação que permaneça inalterada em termos de exposição às condições climáticas: a estação meteorológica fixa. Nesse caso, utilizaram-se dados do Instituto Nacional de Meteorologia (INMET). Devido à falta de dados referentes à Trm, tomaram-se como base os dados horários de $T$ correspondente a cada dia de medição. O procedimento completo de normalização é apresentado em Minella (2009). 


\section{RESULTADOS - ESTUDO 1}

\section{ANÁLISE DA RELAÇÃO ENTRE FVC, ILHA DE CALOR DIURNA E DIFERENÇAS DE TEMPERATURA (DTRM-T)}

Para a verificação da existência de ilha de calor nos locais de experimento (calçadão da Rua XV de Novembro e entorno), foram obtidas as diferenças entre os valores médios de temperatura do ar obtidos nos locais de monitoramento com as médias de temperatura do ar registradas pelo INMET, para todos os dias e para o período das quatro horas correspondentes às medições (12h00, 13h00, $14 \mathrm{~h} 00$ e 15h00). Verificaram-se, também, as diferenças dos valores médios de Trm obtidos por meio das medições e os valores médios de $\mathrm{T}$ medidos pelo INMET $\left(\Delta_{\text {Trm-T }}\right)$, durante o período de monitoramento correspondente. No diagrama de dispersão entre o FVC e a ilha de calor diurna (Erro! Fonte de referência não encontrada.), a correlação foi baixa, quase nula $\left(R^{2}=0,10\right)$. Já em relação às diferenças de temperatura $\left(\Delta_{\text {Trm-T }}\right)$ e o FVC, o coeficiente de determinação foi de 0,35 , com correlação correspondente de 0,59 (Gráfico 14). Esta constatação sinaliza que a Trm, por levar em conta os efeitos da radiação solar, está mais relacionada ao FVC do que a temperatura do ar, embora ambos os valores de correlação tenham sido baixos.

Ainda em relação à análise de Trm e FVC, foram agrupados dados de $\Delta_{\text {Trm-T }}$ em pontos com mesmo valor de FVC, isto é, pontos repetidos durante a campanha de medições. Desta maneira, para os pontos 2 (FVC 0,20); 3 (FVC 0,32); 4 (FVC 0,34); 7 (FVC 0,39); 10 (FVC 0,30) e 14 (FVC 0,55), foram extraídos valores médios de Trm para cada um desses dias. Embora o agrupamento de dados não seja a situação ideal, o agrupamento das diferenças de valores médios de Trm medidos in loco com as médias de T obtidas pelo INMET se justifica por ser a configuração urbana o parâmetro central da pesquisa, não sendo consideradas outras variáveis, como por exemplo, o albedo. Nesse caso, o coeficiente de determinação foi de 0,57 (Erro! Fonte de referência não encontrada.), com correlação correspondente de 0,75 . 


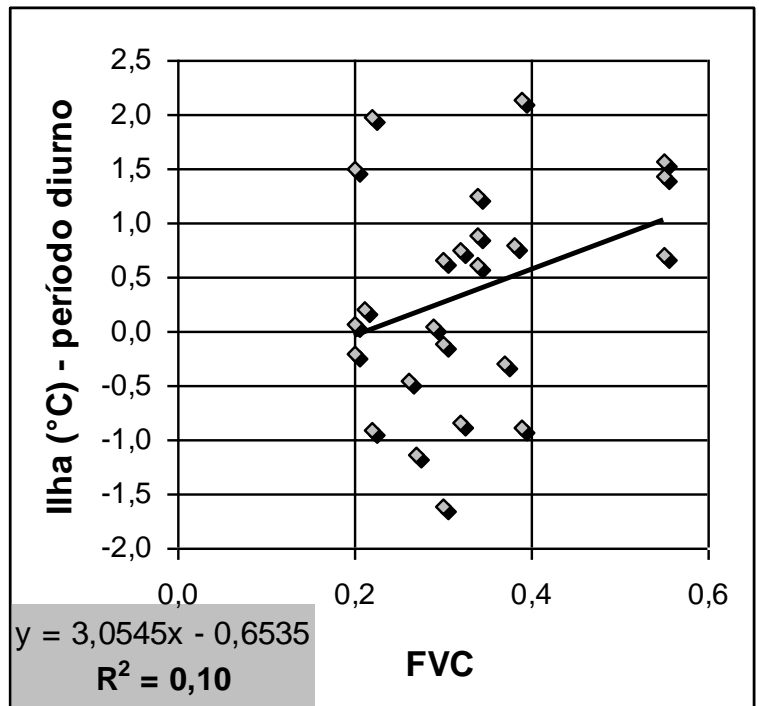

GRÁFICO 1 - GRÁFICO DE DISPERSÃO ENTRE FVC E ILHA DE CALOR DIURNA

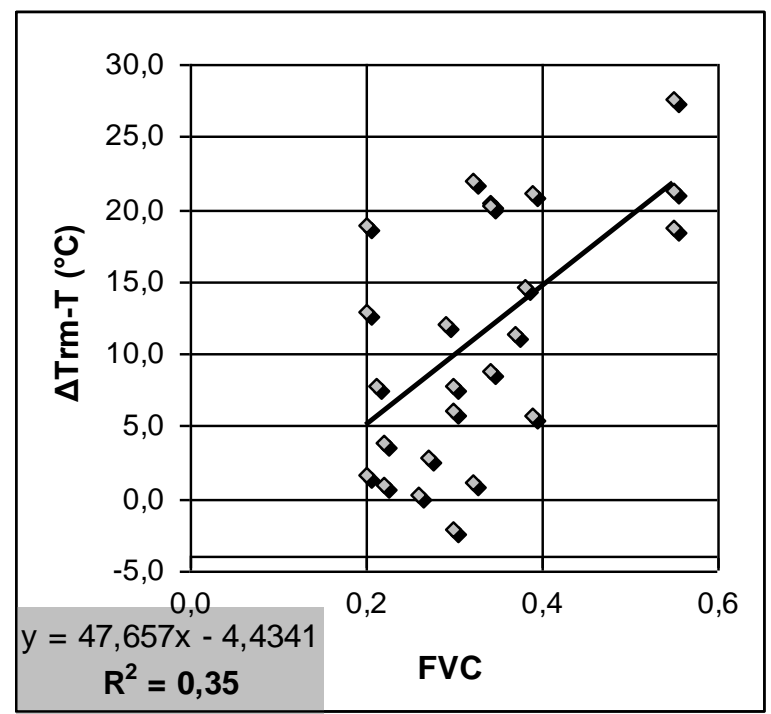

GRÁFICO 2 - GRÁFICO DE DISPERSÃO ENTRE FVC E $\triangle$ TRM-T

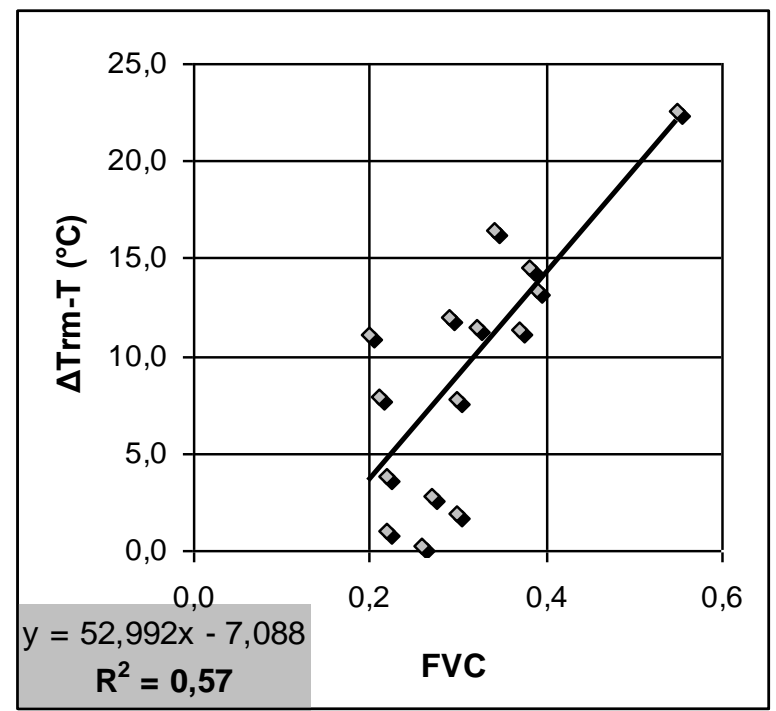

\section{GRÁFICO 3 - GRÁFICO DE DISPERSÃO ENTRE FVC E ILHA DE CALOR DIURNA (DADOS AGRUPADOS)}

As análises demonstram que o FVC não é necessariamente determinante para sensação de conforto no período diurno em razão da diversidade de variáveis climáticas que influem na determinação da $T$ e da 
Trm. Todavia, quando considerado somente o FVC, independente de outras condicionantes, percebe-se que o $\mathrm{R}^{2}$ é mais significativo $(0,57)$.

A partir da análise dos valores médios de ilha de calor e de $\Delta_{\text {Trm-T }}$ do local com maior obstrução (ponto 2, FVC 0,20 ) e do ponto menos obstruído (ponto 14, FVC 0,55), conforme Tabela 1, percebe-se que há uma tendência de que em pontos mais abertos, caso do ponto 14, os valores de temperatura sejam mais elevados, refletindo na formação das ilhas de calor e nas diferenças de temperatura $\Delta_{\text {Trm-T. }}$.

\section{TABELA 1 - FVC, ILHA DE CALOR E DIFERENÇAS DE TEMPERATURA $\left(\Delta_{\text {TRM-T }}\right)$}

\begin{tabular}{ccccc}
\hline DATA & Ponto & FVC & $\begin{array}{c}\text { Ilha (período diurno) } \\
{ }^{\circ} \mathrm{C}\end{array}$ & $\begin{array}{c}\Delta_{\text {Trm-T }} \\
{ }^{\circ} \mathrm{C}\end{array}$ \\
\hline $09 / 01 / 2009$ & 2 & 0,20 & 1,5 & 18,8 \\
$01 / 04 / 2009$ & 2 & 0,20 & 0,1 & 12,9 \\
$17 / 06 / 2009$ & 2 & 0,20 & $-0,2$ & 1,7 \\
$06 / 05 / 2009$ & 14 & 0,55 & 1,4 & 27,6 \\
$03 / 06 / 2009$ & 14 & 0,55 & 1,6 & 21,2 \\
$11 / 08 / 2009$ & 14 & 0,55 & 0,7 & 18,7
\end{tabular}

Sabe-se que uma das questões determinantes para os valores de $\mathrm{T}$ e Trm é a quantidade de radiação incidente no local observado, sendo necessária a análise da acessibilidade solar nestes pontos.

\section{RELAÇÃO ENTRE ACESSIBILIDADE SOLAR E O FVC}

A Trm é uma importante variável no que diz respeito aos índices de conforto térmico, estando diretamente relacionada à radiação solar. Em condições diurnas, conforme verificado nas análises dos pares de medição, o FVC, quando analisado como um parâmetro isolado, não é capaz de predizer as condições térmicas de um determinado local, uma vez que a quantidade de radiação solar influencia sobremaneira os valores de Trm. No entanto, uma análise conjunta do FVC e da radiação solar pode fornecer resultados mais 
precisos quanto ao nível de conforto térmico. Assim, considerando-se a importância da quantidade de radiação solar para a determinação dos valores de Trm, foram feitas interpretações da incidência solar em cada ponto, por meio de cartas solares plotadas sobre as imagens olho de peixe. Tanto as fotos olho de peixe como as cartas solares utilizadas possuem projeção eqüidistante, sendo as trajetórias solares traçadas individualmente para cada dia de medição com auxílio do programa Rayman.

A carta solar sobreposta à foto olho de peixe indica o período de incidência solar no ponto durante todo $\mathrm{o}$ ano. A Figura 4 mostra a trajetória solar do ponto 2 (FVC 0,20), medido no dia 09/01/2009 e do ponto 14 (FVC 0,55), monitorado no dia 03/06/2009. Em ambos os pontos a quantidade de horas de sol é a mesma (aproximadamente 7 horas). Assim, embora a diferença de FVC entre os pontos seja considerável, e as medições tenham ocorrido em épocas distintas, a quantidade de radiação recebida foi semelhante. Considerando-se o período de medição, das 11 h01 até às $15 \mathrm{~h} 00$, o total de radiação incidente no ponto 2 foi de $2449 \mathrm{~W} / \mathrm{m}^{2}$. No ponto 14 , o somatório de radiação incidente no período de monitoramento foi de 2626 $\mathrm{W} / \mathrm{m}^{2}$. As variações na ilha de calor e nas diferenças de temperatura $\Delta_{T \mathrm{rm} \text { - }}$ para ambos os dias (Tabela 1) mostram o impacto da geometria urbana na temperatura ambiente.

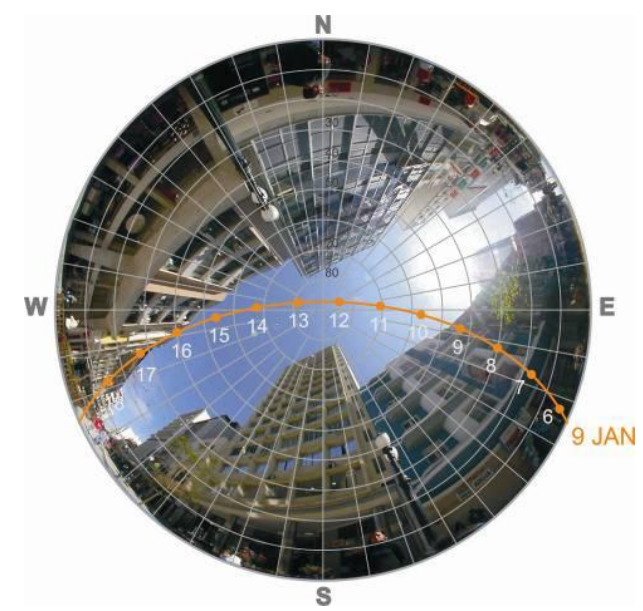

PONTO 2

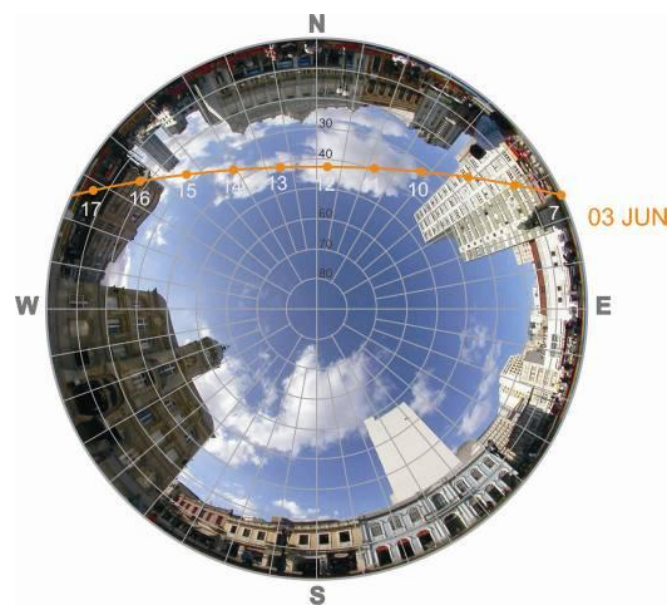

PONTO 14

FIGURA 4 - FOTO OLHO DE PEIXE COM CARTA SOLAR PARA OS PONTOS 2 E 14 
$\mathrm{Na}$ análise da carta solar sobreposta a foto olho de peixe, é atestado que, embora o FVC possa auxiliar na definição da forma urbana, este é um parâmetro limitado para descrever as irregularidades da geometria urbana, ainda que seja um avanço quando comparado a simplificação da relação $H / W$. Pois a radiação solar pode atingir de maneiras distintas pontos com valores de FVCs semelhantes. Assim, verifica-se que a questão da acessibilidade solar adquire grande importância em se tratando de estudos de conforto térmico em espaços abertos.

\section{IMPACTOS DA ORIENTAÇÃO DAS VIAS NA DISPERSÃO DE POLUENTES - ESTUDO 2}

A influência do ambiente construído sobre os processos atmosféricos tem sido objeto de pesquisa há várias décadas. Entende-se que o ambiente construído "envolve a transformação das características radiativas, térmicas, de umidade e aerodinâmicas, e assim afeta os fluxos solares e hidrológicos naturais" (OKE, 1978) das áreas urbanas. Trabalhos subsequentes do mesmo autor detalham as minúcias de camadas verticais e escalas horizontais, inclusive a noção de uma sub-camada de rugosidade - roughness sub layer (RSL), mais próxima ao solo, na qual o fluxo de ar sofre a máxima interferência das estruturas naturais e antrópicas (OKE, 2006).

Não se pode falar de uma configuração urbana "típica": características históricas, culturais e naturais influenciam a morfologia de qualquer assentamento humano (MONTEIRO, 2003). No entanto, zonas climáticas urbanas podem ser agrupadas em classes com características semelhantes de tipologia construtivas, uso e permeabilidade do solo. Segundo a taxonomia proposta por Oke (2006), a área de interesse deste estudo pode ser classificada como Classe 2: "urbana de alta densidade, intensivamente desenvolvida com edifícios de 2 a 5 andares contíguos ou pouco espaçados frequentemente de pedra ou alvenaria". 


\section{QUALIDADE DO AR NA CAMADA LIMITE DE COBERTURA (URBAN CANOPY LAYER)}

A poluição atmosférica pode ter origem natural (incêndios florestais, erupções vulcânicas, tempestades de areia) ou ser ocasionada pela ação humana, Seja qual for sua origem, "os poluentes são substâncias que, sob certas condições, podem ser nocivos a seres humanos, vida animal e vegetal, microorganismos ou aos materiais, ou que podem interferir na qualidade de vida ou usufruto de edifícios e paisagens" (OKE, 1978).

No ambiente urbano, o fluxo do vento (e, consequentemente, as condições para difusão e mistura verticais e horizontais) é afetado pela presença de edifícios, vegetação e outras características. Os efeitos cumulativos da convergência de múltiplas fontes de poluentes e a existência de áreas de estagnação podem levar à formação de locais de concentração de poluição que fogem às medições de poluentes em mesoescala, sendo a dimensão vertical da dispersão de poluentes frequentemente ignorada (WANG et al., 2008)

Monóxido de nitrogênio (NO), dióxido de enxofre $\left(\mathrm{SO}_{2}\right)$ e monóxido de carbono (CO), originários da queima de combustíveis, são considerados poluentes primários, enquanto ozônio $\left(\mathrm{O}_{3}\right)$ e dióxido de nitrogênio $\left(\mathrm{NO}_{2}\right)$ se formam na atmosfera a partir de reações químicas envolvendo substâncias precursoras sob os efeitos da radiação solar ${ }^{5}$. Materiais particulados se originam da combustão do óleo diesel, desgaste dos pneus e freios de veículos, além de processos naturais e fabris.

Quanto ao efeito desses gases à saúde humana, o dióxido de enxofre está relacionado a doenças respiratórias e à chuva ácida; o monóxido de carbono - resultado da combustão incompleta - é extremamente tóxico e causa mortes por asfixia; o ozônio, na baixa atmosfera, é gerado em uma reação fotoquímica envolvendo óxidos de nitrogênio, monóxido de carbono e hidrocarbonetos, sendo um gás irritante e oxidante também associado a doenças respiratórias. Material particulado menor do que $10 \mu \mathrm{m}$ pode ser 
inalado e está associado a asma, problemas cardiovasculares, câncer de pulmão e mortes prematuras.

O monóxido de nitrogênio (NO) é uma substância envolvida em vários processos patológicos e fisiológicos em mamíferos, tanto benéficos como prejudiciais, e pode se tornar tóxico em altas concentrações; na atmosfera, essa substância se combina rapidamente com ozônio livre, gerando $\mathrm{NO}_{2}$ (substância tóxica se inalada e causadora de baixa visibilidade) e $\mathrm{O}_{2}$.

Enquanto as normas nacionais de qualidade do ar estabelecem valores máximos para a concentração de dióxido de nitrogênio $\left(\mathrm{NO}_{2}\right)$, as normas de emissão de poluentes por veículos automotores regulam as emissões de óxidos de nitrogênio totais, $\mathrm{NO}_{x}$ (BRASIL, 1993 e 2002; IAP, 2009). Optou-se, desta forma, pelos óxidos de nitrogênio $\left(\mathrm{NO}_{\mathrm{x}}\right)$ como substância foco deste estudo. A determinação da razão $\mathrm{NO}_{2} / \mathrm{NO}_{x}$, entretanto, supera a capacidade do ENVI-met. Geralmente se adota o valor de $5 \%$ para essa razão. No entanto, medições ao longo de estradas de tráfego intenso e em áreas urbanas na região de Baden-Württemberg (Alemanha) mostraram que essa razão pode atingir 25\% (KESSLER; NIEDERAU; SCHOLZ, 2006), podendo-se adotar este valor como referência para o presente estudo.

A legislação brasileira sobre qualidade do $\operatorname{ar}^{6}$ define dois padrões para a concentração de poluentes. O padrão primário é o limite legal superior para a presença de contaminantes para a salvaguarda da saúde pública, mas não leva em consideração as necessidades da fauna e flora. O padrão secundário representa o limite corrente abaixo do qual ocorrem poucos danos à saúde pública, vida animal e vegetal, materiais e meio-ambiente (IAP, 2009)

\footnotetext{
${ }^{5}$ Para uma explicação mais completa desses processos, ver Oke (1978).

${ }^{6}$ No Brasil, a qualidade do ar é regulamentada pelas Resoluções IBAMA no. 348/1990, CONAMA 03/90. No Paraná, a Resolução SEMA 054/2006 replica os padrões nacionais.
} 


TABELA 2 - PADRÕES PRIMÁRIOS E SECUNDÁRIOS
\begin{tabular}{cccc} 
ATMOSFÉRICOS NO PARANÁ & (ADAPTADO DE IAP, 2009) & POLUENTES \\
\hline Substância & $\begin{array}{c}\text { Tempo de } \\
\text { amostragem }\end{array}$ & $\begin{array}{c}\text { Padrão } \\
\text { primário } \\
\left(\mu \mathrm{g} / \mathrm{m}^{3}\right)\end{array}$ & $\begin{array}{c}\text { Padrão } \\
\text { secundário } \\
\left(\mu \mathrm{g} / \mathrm{m}^{3}\right)\end{array}$ \\
\hline Material Particulado $\left(\mathrm{MP}_{10}\right)$ & $24 \mathrm{~h}$ & 150 & 150 \\
$\mathrm{SO}_{2}$ & $24 \mathrm{~h}$ & 365 & 100 \\
$\mathrm{CO}$ & $24 \mathrm{~h}$ & 40.000 & 40.000 \\
$\mathrm{O}_{3}$ & $1 \mathrm{~h}$ & 160 & 160 \\
$\mathrm{NO}_{2}$ & $1 \mathrm{~h}$ & 320 & 190 \\
\hline
\end{tabular}

\section{MONITORAMENTO DA QUALIDADE DO AR EM CURITIBA}

Danni-Oliveira (2003) estudou a influência dos aspectos geo-ambientais e dos atributos urbanos na dispersão de poluentes no inverno através da análise de amostras coletadas entre 1996 e 1998. Amostras foram coletadas em áreas representativas de diferentes estruturas urbanas: área central de alta densidade, áreas residenciais e áreas rurais. Apesar de se prender a somente uma estação, o estudo mostrou claramente a influência da urbanização e do uso do solo nas concentrações das substâncias analisadas.

A qualidade do ar na Região Metropolitana de Curitiba (RMC) é atualmente monitorada pelo IAP (Instituto Ambiental do Paraná) em treze estações de coleta, uma delas nas proximidades da Praça Rui Barbosa, área central de Curitiba. Em 2008, a qualidade do ar na cidade foi predominantemente boa, com algumas instâncias de concentrações altas de $\mathrm{NO}_{2}$ e $\mathrm{O}_{3}$ nessa estação (IAP 2009).

\section{PROCEDIMENTOS DE SIMULAÇÃO}

A ferramenta de simulação microclimática ENVI-met foi usada para o estudo dos fenômenos climáticos em micro e topoescala em duas ruas na área central de Curitiba. Dados concatenados de plantas da cidade, fotos de satélite e inspeções visuais foram utilizados para a construção do modelo; dados climáticos registrados ao nível do pedestre foram utilizados para a calibragem 
e aferição do modelo. Os efeitos das tipologias construtivas, áreas verdes e arborização também foram levados em consideração.

O ENVI-met é uma ferramenta de simulação microclimática projetada para avaliar as interações entre plantas, superfícies e o ar em escalas espaciais de 0,5 a $10 \mathrm{~m}$ e escala temporal de $10 \mathrm{~s}$, e está em desenvolvimento contínuo. Segundo Bruse (2009), o modelo é capaz de lidar com os aspectos de fluxo de ar em torno de e entre edifícios, turbulência e dispersão de partículas e substâncias, de interesse para o presente estudo. Optou-se por esse modelo por tratar-se de uma ferramenta gratuita (freeware).

Como exemplos de aplicação do modelo: Ali-Toudert (2005) revisou em profundidade o modelo matemático por trás do ENVI-met em suas simulações de cânions urbanos em clima quente e seco. Spangenberg et al. (2008) analisaram a influência da vegetação no conforto térmico na cidade de São Paulo, através de medições in loco e simulações. Dados de temperatura coletados ao nível da rua ( $1 \mathrm{~m}$ acima do solo) foram usados para verificar a acuidade do modelo. Apesar da crescente adoção deste modelo e sua facilidade de uso, ainda há carência de estudos que confrontam medições em campo e resultados da simulação.

Discute-se inicialmente o procedimento de calibração do modelo de simulação a partir de dados de vento coletados ao longo das medições de campo descritas em 3.1. Como variável para comparações, adotou-se a velocidade média de vento (medida versus simulada) medida nos diversos pontos monitorados.

Em seguida, é enfocado o estudo da dispersão de óxidos de nitrogênio $\mathrm{NO}_{2}$ provenientes do escape de veículos, por meio de simulações a partir das funções de dispersão de poluentes, presentes no ENVI-met. Os resultados de três diferentes cenários de simulação - estagnação, ventos oriundos do norte e leste - são analisados e discutidos, em comparação com os padrões nacionais de qualidade do ar. 


\section{MODELAGEM DA REGIÃO DE INTERESSE}

Um trecho de $1440 \mathrm{~m} \times 600 \mathrm{~m}$ da região central de Curitiba foi modelado a partir das plantas cadastrais da PMC, fotografias de satélite e inspeção visual da área de interesse. Utilizou-se o software Eddi, um editor de modelo dedicado incluído no pacote ENVI-met.

Plantas de loteamento cobrindo 70 quadras no entorno da área monitorada foram impressas na escala de 1:2000; cada setor foi percorrido a pé e o número de andares de cada edificação foi contado visualmente. Aproximações foram necessárias devido às diferenças de idade das edificações existentes e foi adotado $3 \mathrm{~m}$ como altura padrão entre pisos. Como - ENVI-met permite um grid com até 30 unidades na vertical, edifícios com mais de 25 pavimentos foram modelados com 75 metros de altura (25 unidades) para garantir espaço livre suficiente no topo do modelo. Áreas gramadas e pavimentadas também foram incluídas, bem como massas de árvores.

Para a simulação da dispersão de poluentes, são necessários dados adicionais acerca do volume de tráfego, distribuição horária de tráfego, composição da frota, taxas de emissão das substâncias de interesse (por veículo). Os dados climáticos são entrados em um arquivo de configuração (.CF) - temperatura, velocidade e direção do vento e outros parâmetros.

Estudos sobre 0 perfil de tráfego em áreas urbanas são inesperadamente raros. Apesar de ser um aspecto importante para as questões de dispersão de poluentes, muito do que se publica sobre distribuição horária de tráfego vem do campo da acústica, como o estudo de Mansouri, Pourmahabadian e Ghamsekani (2006) sobre o ruído de tráfego em áreas centrais de Teerã. Um método indireto para a determinação dos perfis diários de tráfego foi adotado, utilizando-se dados históricos de pressão sonora (BORTOLI, 2002), modelos de predição de ruído de tráfego (CALIXTO, 2002) e períodos curtos de contagem de veículos. O tráfego de motocicletas, veículos leves e pesados foi contado visualmente no horário de pico (17 às 19h), em 
três cruzamentos, por períodos de $15 \mathrm{~min}$ e os resultados extrapolados para uma hora, em acordo com orientações do DER.

Para a conversão de níveis de ruído em volumes de tráfego (em veículos/hora, necessário para a estimativa de emissões), foi utilizado o modelo de Calixto (2002) para predição de ruído de tráfego (Equação 2) ${ }^{7}$ :

$$
L_{e q}=7.7 \cdot \log [I \cdot(1+0.095 \cdot V P)]+43
$$

Equação 2

Sendo $L_{e q}$ o nível de ruído equivalente, I a intensidade de tráfego (em veículos/hora), e VP a porcentagem de veículos pesados. Com o uso desse modelo, um padrão horário de tráfego e um fator de ajuste horário de emissões puderam ser estimados.

Diferentes domínios (de 240x100 a 40x40 unidades) e resoluções $(6 \times 6 \times 3 \mathrm{~m}$ e $3 \times 3 \times 3 \mathrm{~m})$ foram avaliados para se determinar o ajuste ótimo (chegando-se a um equilíbrio adequado entre grau de complexidade de modelo e tempo de processamento). As várias versões do modelo foram executadas usando-se os mesmos dados de entrada e os resultados foram comparados entre si. A versão 3.1 beta 4 do ENVI-met, rodando no MS Windows Vista, foi utilizada em todas simulações. Um domínio de modelo com 230x60 unidades de $6 \times 6 \times 3 m$ foi finalmente selecionado, uma vez que resoluções mais altas e domínios mais amplos não aumentaram a acuidade do modelo.

\footnotetext{
${ }^{7}$ Calixto propõe uma equação mais simples que não leva em consideração a porcentagem de veículos pesados:

$L_{e q}=9.5 \cdot \log (I)+41.4$
} 


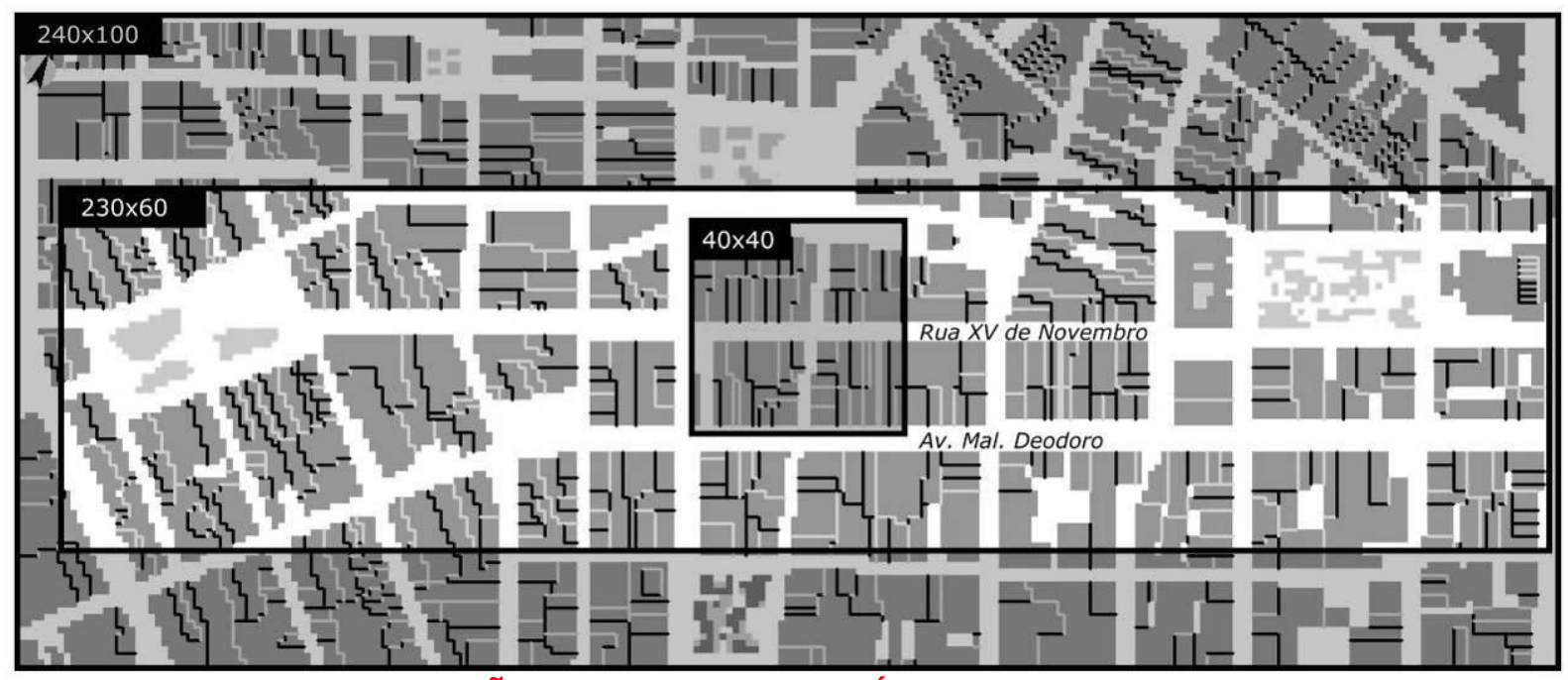

FIGURA 5 - COMPARAÇÃO ENTRE OS DOMÍNIOS DE MODELO

\section{CALIBRAÇÃO DO MODELO}

Grande parte das tentativas de verificação da acuidade do modelo ENVI-met concentra-se nas temperaturas do ar (SPANGENBERG et al., 2008; HEDQUIST et al., 2009). No caso presente, uma vez que o estudo se refere à dispersão de poluentes no nível da rua, a velocidade média de vento medida a $2,1 \mathrm{~m}$ de altura foi selecionada como variável de interesse. Devido à natureza turbulenta do fluxo de vento dentro da RSL, a direção do vento nesta altura foi ignorada.

Receptores virtuais foram incorporados ao modelo em locais correspondentes aos pontos de medição. A velocidade do vento simulada a 2,1m de altura em cada receptor no final da hora simulada foi então comparada com a velocidade média medida. A verificação e ajuste do modelo foram feitos ao longo de múltiplas iterações, alterando-se a geometria do modelo, incluindo-se vegetação e realizando-se ajustes nos parâmetros de entrada.

Assumiu-se que direção do vento da área central de Curitiba semelhante à registrada na estação meteorológica padrão (INMET), ignorando quaisquer efeitos em mesoescala das estruturas urbanas. A velocidade de vento a $10 \mathrm{~m}$ acima do solo (altura padrão de medição, segundo a WMO) é utilizada como entrada no ENVI-met. Os primeiros resultados - obtidos entrando-se os dados 
horários de vento medidos na estação do INMET, sem ajustes - não corresponderam às medições em campo. A Equação 3 foi utilizada para ajustar o perfil logarítmico de vento para um contexto urbano (ALLARD, SANTAMOURIS 1998, p. 90).

$$
\frac{U_{1}}{U_{0}}=K \cdot Z_{1}^{a}
$$

Equação 3

Sendo $U_{0}$ - velocidade média de vento na estação meteorológica, $U_{1}-$ velocidade de vento no ponto de interesse, $Z_{1}$ - altura da medição $(10 \mathrm{~m})$, e $K$ e a são coeficientes de ajuste com valores de 0,21 e 0,33 para ambientes urbanos, respectivamente.

Velocidades médias horárias medidas no INMET foram ajustadas por meio dessa equação e usadas então como dado de entrada para as simulações. Constatou-se que o modelo ENVI-met tende a superestimar a velocidade de vento dentro do cânion quando a velocidade de entrada é maior do que $2 \mathrm{~m} / \mathrm{s}$ (Gráfico 4a). Para velocidades de vento abaixo de $2 \mathrm{~m} / \mathrm{s}$, houve forte convergência entre os valores previstos pelo modelo ENVI-met e as medições in loco (Gráfico 4b). A tabela 3, abaixo, resume os dados de entrada utilizados na fase de calibração do modelo.

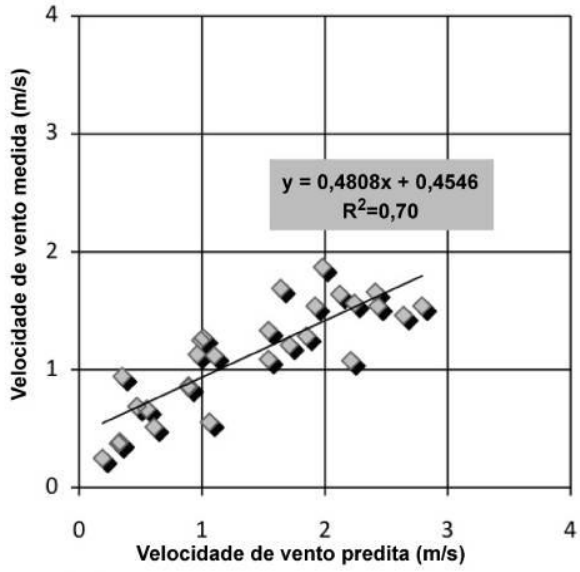

(a)

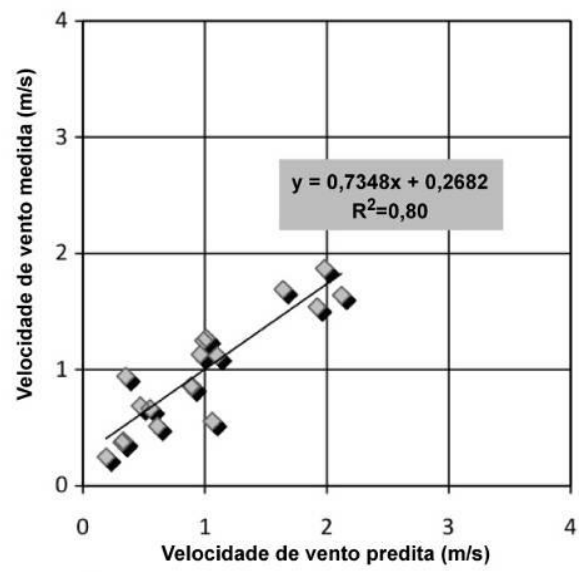

(b)

GRÁFICO 4 - COMPARAÇÃO ENTRE VELOCIDADES MÉDIAS DE VENTO MEDIDAS E PREVISTAS COM O MODELO ENVI-MET: (A) VELOCIDADE DE ENTRADA MAIOR E MENOR QUE $2 \mathrm{M} / \mathrm{S}$; (B) SOMENTE VELOCIDADE DE ENTRADA MENOR QUE 2M/S 
TABELA 3 - PARÂMETROS DE ENTRADA NO MODELO ENVI-MET (ETAPA DE CALIBRAÇÃO)

\begin{tabular}{|c|c|c|c|c|c|c|c|}
\hline Ponto & Data & Hora & $\begin{array}{l}\text { UR } \\
(\%)\end{array}$ & $\begin{array}{c}\text { Temperatur } \\
\text { a inicial da } \\
\text { atmosfera } \\
(\mathrm{K})\end{array}$ & $\begin{array}{c}\text { Umidade } \\
\text { específica } \\
(\mathrm{g} / \mathrm{kg})\end{array}$ & $\begin{array}{l}\bar{u} @ 10 \mathrm{~m} \\
(\text { INMET) }\end{array}$ & Azimute \\
\hline P3 & 25.03 .09 & $11 \mathrm{~h} 00$ & $61 \%$ & 279,8 & 5,22 & 1,39 & $94^{\circ}$ \\
\hline P3 & 25.03 .09 & $12 \mathrm{~h} 00$ & $55 \%$ & 279,8 & 5,22 & 1,48 & $64^{\circ}$ \\
\hline P3 & 25.03 .09 & $13 \mathrm{~h} 00$ & $53 \%$ & 279,8 & 5,22 & 1,84 & $86^{\circ}$ \\
\hline P3 & 25.03 .09 & $14 \mathrm{~h} 00$ & $51 \%$ & 279,8 & 5,22 & 1,62 & $85^{\circ}$ \\
\hline P10 & 25.03 .09 & $11 \mathrm{~h} 00$ & $61 \%$ & 279,8 & 5,22 & 1,39 & $94^{\circ}$ \\
\hline P10 & 25.03 .09 & $12 \mathrm{~h} 00$ & $55 \%$ & 279,8 & 5,22 & 1,48 & $64^{\circ}$ \\
\hline $\mathrm{P} 10$ & 25.03 .09 & $13 \mathrm{~h} 00$ & $53 \%$ & 279,8 & 5,22 & 1,84 & $86^{\circ}$ \\
\hline P10 & 25.03 .09 & $14 \mathrm{~h} 00$ & $51 \%$ & 279,8 & 5,22 & 1,62 & $85^{\circ}$ \\
\hline P3 & 19.06.09 & $11 \mathrm{~h} 00$ & $68 \%$ & 286,4 & 0,24 & 1,08 & $20^{\circ}$ \\
\hline P3 & 19.06.09 & $12 \mathrm{~h} 00$ & $60 \%$ & 286,4 & 0,24 & 1,03 & $24^{\circ}$ \\
\hline P3 & 19.06.09 & $13 \mathrm{~h} 00$ & $56 \%$ & 286,4 & 0,24 & 0,49 & $37^{\circ}$ \\
\hline P3 & 19.06.09 & $14 \mathrm{~h} 00$ & $54 \%$ & 286,4 & 0,24 & 1,08 & $44^{\circ}$ \\
\hline P3 & 19.06.09 & $15 \mathrm{~h} 00$ & $53 \%$ & 286,4 & 0,24 & 0,81 & $14^{\circ}$ \\
\hline P7 & 19.06.09 & $11 \mathrm{~h} 00$ & $68 \%$ & 286,4 & 0,24 & 1,08 & $20^{\circ}$ \\
\hline P7 & 19.06 .09 & $12 \mathrm{~h} 00$ & $60 \%$ & 286,4 & 0,24 & 1,03 & $24^{\circ}$ \\
\hline P7 & 19.06 .09 & $13 h 00$ & $56 \%$ & 286,4 & 0,24 & 0,49 & $37^{\circ}$ \\
\hline P7 & 19.06.09 & $14 \mathrm{~h} 00$ & $54 \%$ & 286,4 & 0,24 & 1,08 & $44^{\circ}$ \\
\hline P7 & 19.06.09 & $15 \mathrm{~h} 00$ & $53 \%$ & 286,4 & 0,24 & 0,81 & $14^{\circ}$ \\
\hline $\mathrm{P} 2$ & 17.06 .09 & $11 \mathrm{~h} 00$ & $65 \%$ & 278,2 & 2,57 & 1,53 & $319^{\circ}$ \\
\hline P2 & 17.06 .09 & $12 \mathrm{~h} 00$ & $60 \%$ & 278,2 & 2,57 & 1,75 & $328^{\circ}$ \\
\hline $\mathrm{P} 2$ & 17.06.09 & $13 \mathrm{~h} 00$ & $59 \%$ & 278,2 & 2,57 & 1,62 & $310^{\circ}$ \\
\hline P2 & 17.06.09 & $14 \mathrm{~h} 00$ & $54 \%$ & 278,2 & 2,57 & 2,24 & $316^{\circ}$ \\
\hline $\mathrm{P} 2$ & 17.06.09 & $15 \mathrm{~h} 00$ & $51 \%$ & 278,2 & 2,57 & 2,34 & $299^{\circ}$ \\
\hline P6 & 17.06 .09 & $11 \mathrm{~h} 00$ & $65 \%$ & 278,2 & 2,57 & 1,53 & $319^{\circ}$ \\
\hline P6 & 17.06 .09 & $12 \mathrm{~h} 00$ & $60 \%$ & 278,2 & 2,57 & 1,75 & $328^{\circ}$ \\
\hline P6 & 17.06 .09 & $13 h 00$ & $59 \%$ & 278,2 & 2,57 & 1,62 & $310^{\circ}$ \\
\hline P6 & 17.06 .09 & $14 \mathrm{~h} 00$ & $54 \%$ & 278,2 & 2,57 & 2,24 & $316^{\circ}$ \\
\hline P6 & 17.06.09 & $15 \mathrm{~h} 00$ & $51 \%$ & 278,2 & 2,57 & 2,34 & $299^{\circ}$ \\
\hline
\end{tabular}

*Dados horários ajustados usando-se a Equação 3

** Medições em campo, nos pontos indicados 


\section{RESULTADOS - ESTUDO 2}

\section{MODELAGEM DA DISPERSÃO DE POLUENTES}

Em 2008, episódios de alta concentração de $\mathrm{NO}_{2}$ foram registrados na área central de Curitiba (IAP, 2009), uma área de tráfego intenso de veículos pesados (ônibus). O modelo ENVI-met exige que dados das fontes de poluentes (taxa de emissão, tipo de substância, tamanho da partícula) sejam incluídos no arquivo SOURCES.DAT. Fontes pontuais, lineares ou de área podem ser modeladas, e as taxas de emissão devem ser ajustadas adequadamente ${ }^{8}$.

Como informações detalhadas do volume de tráfego para a região central de Curitiba não estavam disponíveis, um método indireto para a determinação dos perfis diários de tráfego foi adotado, a partir de dados históricos de pressão sonora (BORTOLI, 2002), modelos de predição de ruído de tráfego (CALIXTO, 2002) e períodos curtos de contagem de veículos. O tráfego de motocicletas, veículos leves e pesados foi contado visualmente no horário de pico (17 às $19 \mathrm{~h}$ ), em três esquinas, por períodos de $15 \mathrm{~min}$ e os resultados extrapolados para uma hora, em acordo com orientações do DER.

A partir das contagens, o tráfego médio verificado por pista, em veículos/hora, foi de 58,3 (motocicletas), 10,6 (veículos leves a Diesel), 443,3 (demais veículos leves) e 14,2 (veículos pesados a diesel), com um total geral de 526,4 veículos/hora por faixa ${ }^{9}$. A porcentagem de veículos pesados no período de contagem foi $2,70 \%$.

O programa nacional de controle de emissões veiculares, Proconve, prevê limites progressivamente menores de emissões para uma mesma substância (BRASIL, 1993 e 2002). Conforme o DETRAN-PR, a média de idade dos veículos registrados em Curitiba é de 10,49 anos (BERTOTTI, 2009);

\footnotetext{
${ }^{8}$ Para fontes lineares, as taxas de emissão devem ser entradas em $\mathrm{mg} / \mathrm{m}$.s. Fontes pontuais exigem taxas de emissão em $\mathrm{mg} / \mathrm{s}$ e $\mathrm{mg} / \mathrm{s} . \mathrm{m}^{2}$, respectivamente.

${ }^{9}$ As principais ruas do modelo têm 3 ou 4 faixas. O tráfego efetivo nessas ruas é 1579 veículos/hora (três faixas) e 2105 veículos/hora (para quatro faixas). O ENVI-met aceita um único valor para a taxa da emissão; assim, adicionar fontes de poluentes conforme o número de faixas permite maior flexibilidade na construção do modelo.
} 
como uma solução de compromisso, os limites superiores definidos pelo CONAMA de emissão de poluentes para maio de 2003 (BRASIL, 1993 e 2002) foram adotados para motocicletas e veículos leves - ou seja, em razão da idade dos veículos em Curitiba, assumiu-se que todos os veículos leves e motocicletas estão atingindo o limite de emissões de $\mathrm{NO}_{x}$ permitidas pela norma.

Quanto às taxas de emissão para veículos pesados, a Resolução CONAMA não estabelece relações entre emissões e distância percorrida ${ }^{10}$, o que dificulta a estimativa dessa variável. Rabl (2002) estudou as emissões de $\mathrm{NO}_{x}$ para veículos pesados na Europa, e adotou-se esse valor para a emissão de $\mathrm{NO}_{x}$, compatível com os limites da norma brasileira. A Tabela 4 resume os valores adotados para as emissões de $\mathrm{NO}_{x}$ para fins de simulação. A taxa de emissão composta, expressa em $\mathrm{mg} / \mathrm{m} . \mathrm{s}$, é o somatório das taxas de emissão por veículo multiplicadas pelo volume de tráfego de cada categoria de veículo, dividida por 3600 para se obter a taxa de emissão por segundo, exigida pelo modelo ENVI-met.

TABELA 4 - EMISSÕES DE NOX PARA MOTOCICLETAS, VEÍCULOS LEVES E VEÍCULOS PESADOS, POR VEÍCULO

\begin{tabular}{cccc}
\hline & \multicolumn{3}{c}{$\mathrm{E}(\mathrm{mg} / \mathrm{m})$} \\
\hline Substância & Motocicletas & Veículos leves & Veículos pesados \\
\hline NOx & $0.18^{*}$ & $0.25 / 1.40^{* *}$ & $21.11^{* * *}$
\end{tabular}

*motores até 151cc (Brasil, 2002)

**Veículos leves a Diesel (Brasil, 1993)

${ }^{* * *} \operatorname{Rabl}(2002)$

\footnotetext{
${ }^{10}$ A Resolução CONAMA 297/2002 estabelece limites de emissão de poluentes em $\mathrm{g} / \mathrm{km}$ (numericamente igual ao valor em $\mathrm{mg} / \mathrm{m}$ ) para os veículos leves e motocicletas. Supõe-se que esses valores se apliquem a veículos novos em condições de uso médio (combinado rodovia e urbano). Considerando condições de congestionamento e o próprio desgaste do motor, assumiu-se um cenário de "pior caso" usando o limite superior da referida Resolução (BRASIL, 2002). Para os veículos pesados, são definidos limites de emissão por kWh de combustível consumido - um valor dependente da potência do veículo, da capacidade calorífica do óleo diesel e da proporção de compostos de nitrogênio no combustível; adotou-se o valor aferido por Rabl (2002) por entendê-lo como uma síntese de todos esses fatores.
} 
Padrões diários de tráfego foram extrapolados usando-se os dados históricos de pressão sonora ${ }^{11}$ nas ruas de Curitiba (BORTOLI 2002), através da Equação 2, e contagem de veículos no período de pico, entre 17h e 19h. A taxa composta de emissão $(0,1211 \mathrm{mg} / \mathrm{m} . \mathrm{s})$ foi multiplicada pelo fator de ajuste de emissão (Tabela 5) e os valores para $X_{\text {NOX }}$ (taxa de emissão horária de $\mathrm{NO}_{\mathrm{x}}$ ) foram incorporados ao arquivo SOURCES.DAT.

TABELA 5 - PERFIL HORÁRIO DE TRÁFEGO PARA A ÁREA CENTRAL DE CURITIBA E TAXAS DE EMISSÃO DE NOX

\begin{tabular}{ccccc}
\hline Hora & $\begin{array}{c}\text { Pressão sonora } \\
(\mathrm{dB}(\mathrm{A}))\end{array}$ & $\begin{array}{c}\text { Porcentagem do } \\
\text { tráfego médio }\end{array}$ & $\begin{array}{c}\text { Fator de ajuste } \\
\text { de emissão }\end{array}$ & $\mathrm{X}_{\text {Nox }}(\mathrm{mg} / \mathrm{ms})$ \\
\hline $15 \mathrm{~h} 00$ & 65.0 & $74 \%$ & 0.74 & 0.0898 \\
$16 \mathrm{~h} 00$ & 65.0 & $74 \%$ & 0.74 & 0.0898 \\
$17 \mathrm{~h} 00$ & 65.0 & $100 \%$ & 1.00 & 0.1211 \\
$18 \mathrm{~h} 00$ & 66.0 & $100 \%$ & 1.00 & 0.1211 \\
$19 \mathrm{~h} 00$ & 66.0 & $100 \%$ & 1.00 & 0.1211 \\
$20 \mathrm{~h} 00$ & 64.5 & $64 \%$ & 0.64 & 0.0773 \\
$21 \mathrm{~h} 00$ & 63.0 & $41 \%$ & 0.41 & 0.0494 \\
\hline
\end{tabular}

Quatro cenários de simulação foram executados: os cenários 1 e 2 correspondem a condições de vento mínimo $(0,30 \mathrm{~m} / \mathrm{s})$. Os cenários 2 e 3 correspondem a condições de vento de norte - aproximadamente perpendicular às ruas estudadas - e leste - aproximadamente paralelo às ruas -, respectivamente. Os parâmetros de entrada estão resumidos na Tabela 6; os demais parâmetros foram mantidos em seus valores padrão. Optou-se pela simulação para o mês de março, próximo ao equinócio de outono, de modo a se reduzir a influência da variação anual do ângulo de incidência solar. A velocidade de vento para os cenários 2 e 3 foi $1,36 \mathrm{~m} / \mathrm{s}$, ajustada de médias históricas de $3,1 \mathrm{~m} / \mathrm{s}$ para o mês de março (LAMBERTS et al., 1998).

\footnotetext{
${ }^{11} \mathrm{O}$ estudo de Bortoli incluiu dados de uma estação de monitoramento de pressão sonora cerca de $500 \mathrm{~m}$ ao sul do domínio do modelo, na área central de Curitiba.
} 
período de cada simulação foi de $6 \mathrm{~h}$, iniciando-se às $15 \mathrm{~h}$; as simulações mostraram que às $19 \mathrm{~h}$ atinge-se a máxima concentração de $\mathrm{NO}_{\mathrm{x}}$. Os valores de concentração a 2,1m de altura foram plotados na Figura 6, juntamente com os histogramas de concentração (ao longo de todo o domínio de modelo).

TABELA 6 - PARÂMETROS DE ENTRADA UTILIZADOS NOS TRÊS CENÁRIOS DE SIMULAÇÃO

\begin{tabular}{cccccc}
\hline Cenário & $\begin{array}{c}\bar{u} @ 10 \mathrm{~m} \\
(\mathrm{~m} / \mathrm{s})\end{array}$ & Azimute & $\begin{array}{c}\text { UR } \\
(\%)\end{array}$ & $\begin{array}{c}\text { Temperatura } \\
\text { inicial da } \\
\text { atmosfera } \\
(\mathrm{K})\end{array}$ & $\begin{array}{c}\text { Umidade } \\
\text { específica } \\
(\mathrm{g} / \mathrm{kg})\end{array}$ \\
\hline $\begin{array}{c}\text { 1. Norte } \\
\text { mínimo }\end{array}$ & 0,30 & $0^{\circ}$ & $60 \%$ & 284,5 & 8,67 \\
\hline $\begin{array}{c}\text { 2. Leste } \\
\text { mínimo }\end{array}$ & 0,30 & $90^{\circ}$ & $60 \%$ & 284,5 & 8,67 \\
\hline $\begin{array}{c}\text { 2. Norte } \\
\text { médio }\end{array}$ & 1,36 & $0^{\circ}$ & $60 \%$ & 284,5 & 8,67 \\
\hline $\begin{array}{c}\text { 3. Leste } \\
\text { médio }\end{array}$ & 1,36 & $90^{\circ}$ & $60 \%$ & 284,5 & 8,67 \\
\hline
\end{tabular}

As simulações mostraram diferenças significativas entre os cenários de vento mínimo e aqueles de vento médio (Figura 6). A dispersão de $\mathrm{NO}_{\mathrm{x}}$ foi de maneira geral melhor com ventos oriundos de norte do que com ventos oriundos de leste, como pode ser visto nos histogramas. A incidência de ventos aproximadamente perpendiculares ao cânion urbano da Rua XV de Novembro parece favorecer a dispersão dos poluentes, enquanto os ventos de leste, aproximadamente paralelos ao cânion, são menos eficientes em misturar e dispersar os poluentes, distribuindo-os ao longo do cânion. 


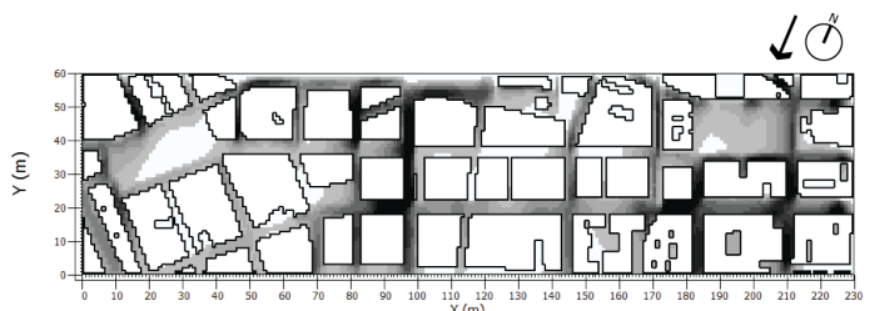

(a)

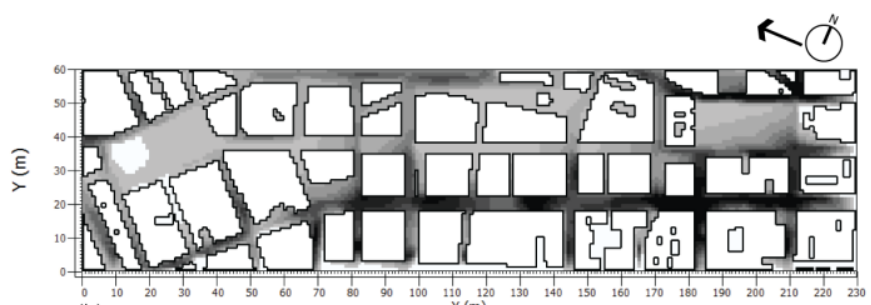

(b)

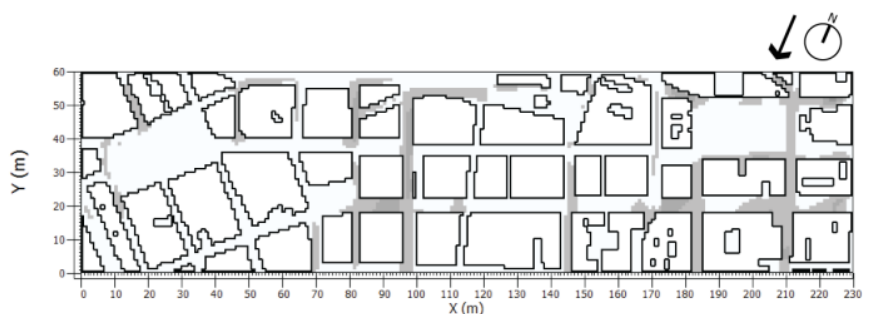

(c)

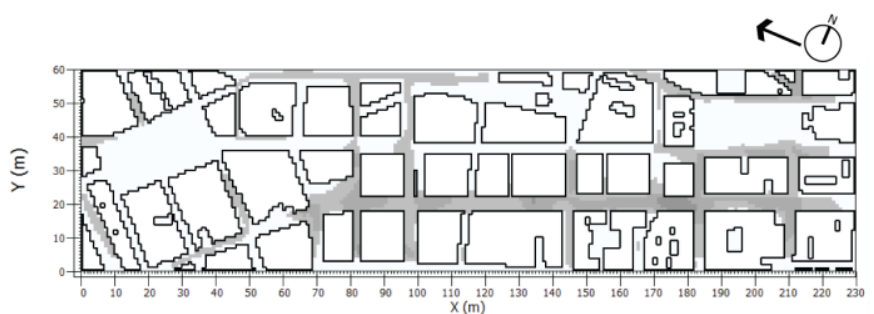

(d)

Concentração de $\mathrm{NO}_{X}$

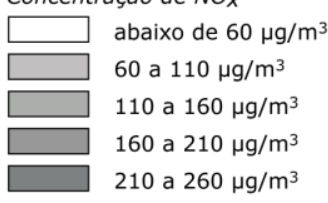

(e)

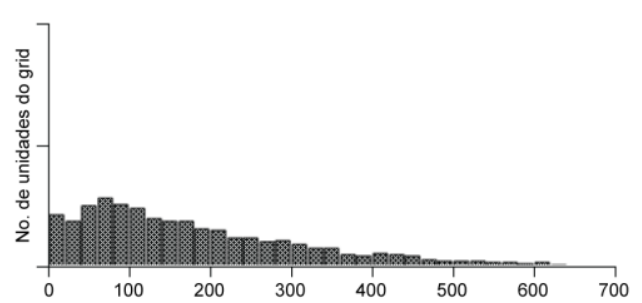

(a)

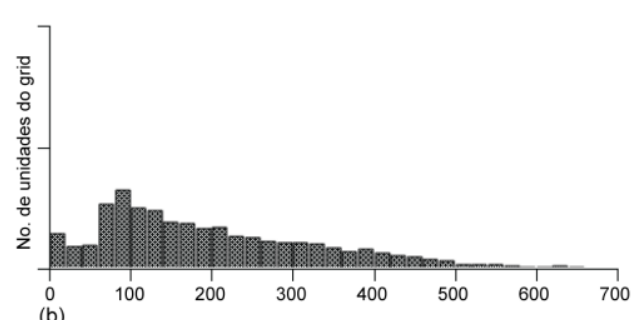

(b)
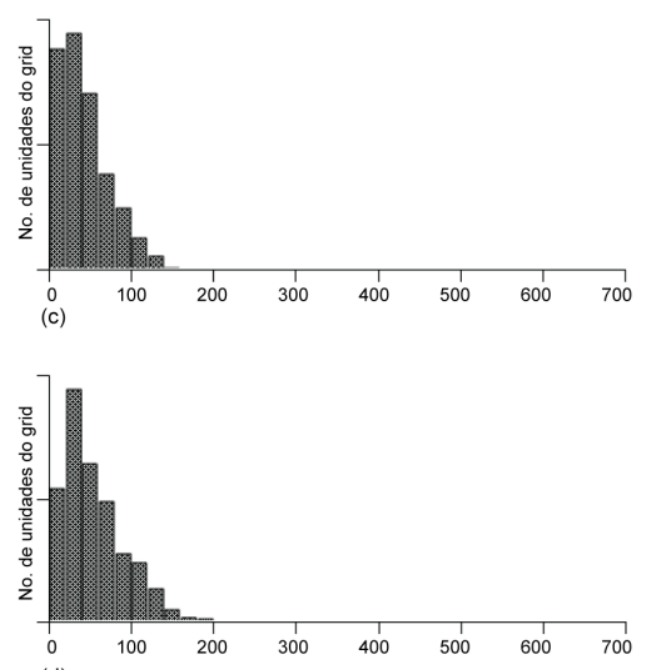

(d)

FIGURA 6 - MAPAS E HISTOGRAMAS DE CONCENTRAÇÃO DE NOx A 2,1M ACIMA DO CHÃO, 19H: (A) CENÁRIO 1; (B) CENÁRIO 2; (C) CENÁRIO 3 (D) CENÁRIO 4 (E) LEGENDA

No cânion da Rua XV de Novembro, concentrações de $\mathrm{NO}_{x}$ simuladas sob vento norte médio ficaram abaixo de $30 \mu \mathrm{g} / \mathrm{m}^{3}$ ao longo da maior parte da rua; no cenário de vento leste médio, a concentração de $\mathrm{NO}_{x}$ simulada foi ligeiramente maior, entre 40 e $60 \mu \mathrm{g} / \mathrm{m}^{3}$ na maior parte da rua.. Concentrações do poluente na Av. Mal. Deodoro foram consideravelmente maiores. As piores 
condições foram encontradas no Cenário 2, sob condições de vento leste mínimo, com concentração de $\mathrm{NO}_{x}$ acima de $400 \mu \mathrm{g} / \mathrm{m}^{3}$ na maior parte do cânion e pico de $646 \mu \mathrm{g} / \mathrm{m}^{3}$; novamente, ventos de norte favoreceram a dispersão de poluentes, com concentrações abaixo de $120 \mu \mathrm{g} / \mathrm{m}^{3}$ no Cenário 3 ao longo da maior parte da rua (exceto alguns hotspots) e dentro da faixa de 60 a $210 \mu \mathrm{g} / \mathrm{m}^{3}$ virtualmente ao longo de todo o cânion no Cenário 4.Como discutido anteriormente, o modelo ENVI-met não é capaz de determinar a razão $\mathrm{NO}_{2} / \mathrm{NO}_{x}$, mas a alta concentração das substâncias precursoras oferece pistas para potenciais locais de concentração do poluente. $O$ estudo de Kessler et al. (2006) mostrou evidências do crescimento da razão $\mathrm{NO}_{2} / \mathrm{NO}_{x}$ em áreas urbanas, de $5 \%$ (em 1995) para $25 \%$. No cenário 2 , se a maior taxa - de $25 \%$ - é adotada, as concentrações de $\mathrm{NO}_{2}$ originárias do tráfego de veículos podem atingir $161 \mu \mathrm{g} / \mathrm{m}^{3}$ - muito próximo do limite definido para o padrão secundário de qualidade do ar. Porém, estudos recentes demonstram que, mesmo variações relativamente pequenas da concentração desta substância (da ordem de uma dezena de $\mu \mathrm{g} / \mathrm{m}^{3}$ ), já causam impactos mensuráveis sobre a saúde da população (IAP 2009; DANNI-OLIVEIRA 2008). Determinar a razão $\mathrm{NO}_{2} / \mathrm{NO}_{x}$ permitiria melhor interpretação desses resultados.

\section{Limitações do modelo}

Quatro limitações do modelo ENVI-met ficaram aparentes durante esse estudo:

- A acuidade do modelo, quanto à velocidade do vento intra-cânion, é reduzida quando a velocidade do vento a $10 \mathrm{~m}$ (parâmetro de entrada) está acima de 2 /ms;

- Não é possível incluir valores de fundo para a concentração de substâncias; valores simulados representam somente as substâncias oriundas das fontes presentes no domínio de modelo;

- Apenas uma substância pode ser simulada por vez, exigindo execuções sucessivas para diferentes substâncias; 
- Finalmente, os perfis de árvores e vegetação incluídos no pacote de software podem não representar corretamente as espécies locais.

\section{CONSIDERAÇÕES FINAIS}

O presente estudo buscou o entendimento de impactos microclimáticos do desenho urbano, apresentando dois estudos na área central de Curitiba.

Nas análises dos níveis de conforto térmico verificou-se que, em dias com temperaturas mais elevadas, pontos com menor obstrução da abóbada celeste, ou seja, com maior valor de FVC, acarretam em maior desconforto por calor. No entanto, estes mesmos pontos podem apresentar melhor situação de conforto em dias com temperaturas mais baixas. A análise da diferença da $T$ obtida in loco pela $T$ registrada pela estação meteorológica de referência (INMET) permitiu a verificação de ilhas de calor em dias com temperaturas mais elevadas e ilhas de frescor em dias com temperaturas mais baixas nos locais monitorados. No entanto, a análise de regressão linear simples, para o FVC e a ilha de calor, apontou para uma correlação nula. Já a análise de regressão linear para as diferenças de temperatura $\left(\Delta_{T \mathrm{rm}-\mathrm{T}}\right)$ apresentou maior coeficiente de determinação. As análises ainda demonstram que, devido à influência de outros parâmetros climáticos, o FVC não é necessariamente determinante para a sensação de conforto térmico no período diurno. Porém, quando considerado somente o FVC (agrupamento de dados de $\Delta_{\text {Trm-T }}$ em pontos que foram monitorados mais de uma vez), independente de outras condicionantes, percebe-se que a correlação é relativamente alta $(R=0,75)$.

A Trm possui relação direta com a quantidade de radiação solar incidente, o que demonstra a importância do desenho urbano para a determinação dos níveis de conforto. $\mathrm{Na}$ análise da carta solar, foi possível verificar uma limitação do FVC, pois este parâmetro quantifica a área de céu disponível, não havendo relação direta com a questão do acesso solar. Assim, a radiação solar pode atingir de maneiras distintas pontos com valores de FVC semelhantes. Cabe ressaltar a influência da radiação difusa relacionada à contribuição da abóbada celeste, na determinação dos valores de Trm. 
Deve-se observar que enquanto a maioria das cidades apresenta maior desconforto por calor, para a cidade de Curitiba faz-se necessário considerar medidas de conforto visando diminuir o desconforto por frio. Desta maneira, no tocante ao conforto térmico das ruas pedonais de Curitiba, deve-se levar em conta que cânions com maiores valores de FVCs terão mais acesso solar e, portanto, temperaturas mais confortáveis do que espaços com restrição à quantidade de céu visível. Além do fato da forma dos cânions influenciarem nos fluxos de vento, o qual está diretamente relacionado à sensação térmica dos transeuntes.

No segundo estudo apresentado, um método para a simulação de dispersão de poluentes em uma área urbana de alta densidade utilizando-se o modelo ENVI-met foi explorado. Uma seção do centro de Curitiba foi modelada, usando-se informações disponíveis - plantas de loteamento e fotos de satélite - e levantamento visual.

Constatou-se que, quando dados de vento representativos obtidos dentro da zona urbana não são disponíveis, medições de vento a partir de estações meteorológicas oficiais (no caso, do INMET) podem ser utilizadas desde que se tome o cuidado de ajustar os dados de entrada, em função das diferenças de rugosidade do terreno. Isso sugere que é possível utilizar o modelo para prever condições dentro do cânion urbano a partir de dados climáticos padronizados.

Os resultados das simulações quanto à dispersão de $\mathrm{NO}_{\mathrm{x}}$ resultaram que as concentrações de $\mathrm{NO}_{x}$ foram significativamente mais altas no cenário de estagnação; os cenários de ventos de norte apresentaram dispersão de $\mathrm{NO}_{x}$ marginalmente melhor que os cenários de ventos de leste.

Apesar de suas limitações, o ENVI-met se mostrou uma ferramenta viável para o estudo de fluxo de ar e dispersão de poluentes em contextos urbanos altamente complexos; o fluxo de trabalho apresentado nesse artigo pode ser facilmente adaptado para a simulação de dispersão de outras substâncias, tais como o $\mathrm{SO}_{2}$ e material particulado. A partir desse cenário base, diferentes geometrias - diferentes políticas de zoneamento e uso do 
solo, por exemplo - e soluções alternativas de tráfego também podem ser exploradas. A análise detalhada dos resultados da simulação pode indicar pontos problemáticos em potencial e sua relação com a morfologia urbana e características climáticas locais.

\section{REFERÊNCIAS}

ABNT - Associação Brasileira de normas técnicas. Projeto de norma 02:136.01.001 - Desempenho de edifícios habitacionais de até cinco pavimentos - Parte 3, 2004.

ALI-TOUDERT, F. Dependence of Outdoor Thermal Comfort on Street Design in Hot and Dry Climate. 2005. 206f. Tese (Meteorologischen Institutes der Universität Freiburg) - Universität Freiburg, Freiburg, 2005. Disponível em: $<$ http://www.freidok.uni-

freiburg.de/volltexte/2078/pdf/Diss_Freidok_Ali_Toudert_Fazia.pdf >. Acesso em: 01 ago. 2009.

ALLARD, F.; SANTAMOURIS, M. (Ed.). Natural Ventilation in Buildings. Londres: James \& James, 1998.

Associação Comercial do Paraná. Calçadão da XV vai brilhar de novo. Curitiba, nov. de 2007.2 Disponível em: $<$ http://www.acpr.com.br/index.php?ID MATERIA=932\&ID TEMPLATE=118\&a =noticia.php>. Acesso em: 20/01/2009.

BERTOTTI, J. N. 40\% dos veículos de Curitiba têm mais de 10 anos. Gazeta do Povo, Curitiba, 9 de Julho 2009.

BORTOLI, P. S. Análise da poluição sonora urbana em zoneamentos distintos da cidade de Curitiba. Dissertação (mestrado). Programa de PósGraduação em Tecnologia, Universidade Tecnológica Federal do Paraná, Curitiba, 2002. Disponível em: < http://www.ppgte.ct.utfpr.edu.br/dissertacoes/2002/bortoli.pdf>. Acesso em 16/09/2009.

BRASIL. Conselho Nacional do Meio Ambiente. Resolução CONAMA no. 297/2002, $26^{\text {th }}$ of February 2002. Estabelece os limites para emissões de 
gases poluentes por ciclomotores, motociclos e veículos similares novos. Diário Oficial [da] República Federativa do Brasil. Brasília, 2002.

BRASIL. Lei Federal no. 8723, 28th of October 1993. Dispõe sobre a redução de emissão de poluentes por veículos automotores e dá outras providências. Diário Oficial [da] República Federativa do Brasil. Brasília, 1993.

BRUSE, M. ENVI-met website. <http://www.envi-met.com>. Acesso em $11 / 2009$.

CALIXTO, A. O ruído gerado pelo tráfego de veículos em "rodoviasgrandes avenidas" situadas dentro do perímetro urbano de Curitiba, analisado sob parâmetros acústicos objetivos e seu impacto ambiental. Dissertação (mestrado). Curso de Pós-Graduação em Engenharia Mecânica, Universidade Federal do Paraná, Curitiba, 2002. Disponível em: < http://www.pgmec.ufpr.br/dissertacoes/dissertacao 002.pdf>. Acesso em 12/02/2010.

CAMPBELL, S. Application Note: Weather Station Siting and Installation Tools. 1997.

CHAPMAN, L. et al. Potential applications of thermal fisheye imagery in urban environments. Geoscience and Remote Sensing Letters. IEEE Geoscience and Remote Sensing Letters, v.4, n. 1, p. 56-59, 2007.

CHAPMAN, L. Towards a tree-view factor. Why do urban climatologists dislike trees? IAUC Newsletter, v. 25, p. 4-6, 2007.

CHAPMAN, L.; THORNES, J. E. Real-time sky-view factor calculation and approximation. J. Atmos. Oceanic. Technol., v. 21, n.5, p. 730-742, 2004.

CHAPMAN, L.; THORNES, J. E.; BRADLEY, A. V. Rapid determination of canyon geometry parameters for use surface radiation budgets. Theoretical Appl. Climatol., v. 69, n.1-2, p. 81-89, 2001.

CORREA, E. N. et al . Evaluación del factor de visión de cielo a partir del procesamiento digital de imágenes hemiesféricas. Influencia de la configuración del canón urbano en la disponibilidad del recurso solar. Avances en Energías Renovables y Medio Ambiente, v.9, p. 43-48, 2005. 
DANNI-OLIVEIRA, I. M. A Cidade de Curitiba e a Poluição do Ar: Implicações de seus atributos urbanos e geoecológicos na dispersão de poluentes em período de inverno. In: MONTEIRO, C. A. F.; MENDONÇA, F. Clima Urbano. São Paulo: Contexto, 2003.

DANNI-OLIVEIRA, I. M. A Poluição do Ar como Causa de Morbidade e Mortalidade da População Urbana. Revista Ra 'E Ga, Curitiba, n. 15, p.113126. 2008.

ELIASSON, Ingegärd. Urban Nocturnal Temperatures, Street Geometry and Land Use. Atmos. Environ. , v. 30, p. 379-392, 1996.

HAN, S.; MUN, S.; HUH, J. (2007). Changes of the micro-climate and building cooling load due to the green effect of a restored stream in Seoul, Korea. In: 10th International Building Performance Simulation Association Conference and Exhibition, 2007, Beijing, China. Proceedings... Beijing, China: IBPSA.

HEDQUIST, B. C. BRAZEL, A. J. DI SABATINO, S. CARTER, W. FERNANDO, H. J. S. Phoenix Urban Heat Island Experiment: Micrometeorological Aspects. In: Eigth Symposium on the Urban Environment. 89th American Meteorological Society Annual Meeting, Phoenix (2009). Joint Session 12, Disponível em from: <http://ams.confex.com/ams/ 89annual/techprogram/paper 145712.htm>

IBGE. Cidades. Disponível em: <http://www.ibge.gov.br/cidadesat>. Acesso em: 21 jun. 2009.

INSTITUTO AMBIENTAL DO PARANÁ (IAP). Relatório Qualidade do Ar na Região Metropolitana de Curitiba, Ano de 2008. Paraná, 2009.

INSTITUTO DE PESQUISA E PLANEJAMENTO URBANO DE CURITIBA (IPPUC). Website. <http://ippuc.org.br>. Acesso em 11/ 2009.

ISO 7726 Ergonomics of the Thermal Environment: Instruments of measuring physycal quantities. ISO, 1998.

ISO 8896 Ergonomics of the Thermal Environment: Determination of metabolic rate. Suiça: ISO, 2004. 
JOHNSON, G. T.; WATSON, I. D. The determination of view-factors in urban canyons. Journal of Applied Climate and Meteorology, v. 23. p. 329-335, 1984.

KESSLER, C. NIEDERAU, A. SCHOLZ, W. Estimation of $\mathrm{NO}_{2} / \mathrm{NO}_{x}$ relations of traffic emissions in Baden-Württemberg from 1995 to 2005. In: 2nd conf. Environment \& Transport, incl. 15th conf. Transport and Air Pollution. Reims, France, 12-14 June 2006. Proceedings no. 107, Vol. 2, Arceuil, França: Inrets, 2006.

LAMBERTS, R. GOULART, S. FIRMINO, S. Dados Climáticos Para Projeto e Avaliação Energética de Edificações Para 14 Cidades Brasileiras. Florianópolis: UFSC, 1998.

MANSOURI, N. POURMAHABADIAN, M. GHAMSEKANI, M. Road Traffic Noise in Downtown Area of Tehran. Iran. J. Environ. Health. Sci. Eng., v. 3, n. 4, p. 267-272. Irã, 2006.

MINELLA, F. O. Avaliação da influência de aspectos da geometria urbana sobre níveis de conforto térmico em ruas de pedestres de Curitiba. 2009. 163 f. Dissertação (Mestrado em Programa de Pós Graduação em Tecnologia) - UTFPR, 2009.

MONTEIRO, C. A. F. Teoria e Clima Urbano: um projeto e seus caminhos. In: MONTEIRO, C. A. F.; MENDONÇA, F. Clima Urbano. São Paulo: Contexto, 2003.

OKE, T. R. Boundary layer climates. Nova York: Methuen, 1978.

OKE, T. R. Initial guidance to obtain representative meteorological observations at urban sites. Genebra: WMO, 2006.

OKE, T. R. Canyon geometry and the nocturnal urban heat island: comparison of scale model and field observations. Journal of Climatology, v. 1 p. 237254, 1981.

RABL, A. Environmental benefits of natural gas for buses. Transportation Research Part D: Transport and Environment, v. 7, n. 2, 2002. 
SOUZA, L. C. L. Thermal environment as a parameter for urban planning. Energy Sustainable Development, v. XI n.4, p. 44-53, 2007.

SOUZA, L. C. L.; RODRIGUES, D. S.; MENDES, J. F. G. Expandindo um SIGD para aplicação em conforto ambiental em nível urbano. In: VII Encontro Nacional sobre Conforto no Ambiente Construído e III Conferência LatinoAmericana sobre Conforto e Desempenho Energético de Edificações,8, 2003, Curitiba. Anais...Curitiba: ANTAC, 2003. p. 669-676.

SPANGENBERG, J. et. al. Simulation of the influence of vegetation on microclimate and thermal comfort in the city of São Paulo. Revista SBAU, Piracicaba, v. 3 n. 2, Jun. 2008.

SVENSSON, M. K. Sky view factor analysis - implications for urban air temperature differences. Meteorol. Appl., v. 11, p. 201-211, 2004.

THORSSON, S. et al. Different methods for estimating the mean radiant temperature in an outdoor urban setting. International Journal of Climatology. n.27. p.1983-1993, 2007.

UNGER, J. Intra-urban relationship between surface geometry and urban heat island: review and new approach. Clim Res, v. 27, p. 253-264, 2004.

UPMANIS, H.; CHEN, D. Influence of geographical factors and meteorological variables on nocturnal urban - park temperature - differences - A case study of summer 1995 in Göteborg, Sweden. Clim Res, v. 13, p. 125-139, 1999.

WANG, G.; BOSCH, F. H. M.; KUFFER, M. Modelling Urban Traffic Air Pollution Dispersion. The International Archives of the Photogrammetry, Remote Sensing and Spatial Information Sciences. Vol. XXXVII, Part B8, 2008. 